\title{
Context and perceptual asymmetry effects on the mismatch negativity (MMNm) to speech sounds: an MEG study
}

Andreas Højlund ${ }^{\mathrm{a}, \mathrm{b}, \mathrm{c} *}$, Line Gebauer ${ }^{\mathrm{a}, \mathrm{b}}$, William B. McGregor ${ }^{\mathrm{c}}$, Mikkel Wallentin ${ }^{\mathrm{a}, \mathrm{b}, \mathrm{c}}$

${ }^{a}$ Center of Functionally Integrative Neuroscience, Aarhus University Hospital, Aarhus, Denmark

${ }^{b}$ Interacting Minds Centre, Aarhus University, Aarhus, Denmark

${ }^{c}$ Department of Linguistics, Cognitive Science and Semiotics, Aarhus University, Aarhus, Denmark

* Corresponding author. Center of Functionally Integrative Neuroscience (CFIN), Aarhus University Hospital, Nørrebrogade 44, Build. 10G-4, DK-8000 Aarhus C, Denmark; e-mail: hojlund@cfin.au.dk; phone: +45 78464398.

Running head: "Perceptual asymmetry reflected by the MMNm to speech"

Word count (including main text and figure/table captions): 9,086 


\title{
Context and perceptual asymmetry effects on the mismatch negativity (MMNm) to speech sounds: an MEG study
}

\begin{abstract}
The mismatch negativity (MMN) of the auditory ERP/ERF has been shown to be sensitive to both phonetic and phonological contrasts. However, potential asymmetry effects and effects of the immediate phonetic contexts on this neural sensitivity are understudied phenomena.

Using magnetoencephalography (MEG), we attempted to address this lacuna by investigating native Danish listeners' MMNm to the phonological contrast between the consonants / $/$ / and / $/$ / in two different phonetic contexts in Danish: one word-initial, preserving the contrast's phonemic status, and another wordfinal, neutralizing it.

We found no support for effects of the immediate phonetic context on the MMNm. However, we observed an asymmetry effect for the phonological contrast: Hearing [t] among [d]s elicited a significantly stronger MMNm than hearing [d] among [t]s. This asymmetry effect was mirrored in a behavioral oddball-detection task showing reduced sensitivity for hearing [d] among [t]s. We discuss both psychoacoustic aspects and phonological underspecification as potential explanations.
\end{abstract}

Keywords: mismatch negativity (MMN); MEG; perceptual asymmetry; underspecification; phoneme; allophone; phonetic context 


\section{Introduction}

A cornerstone in human speech perception is the ability to discriminate between phonemic sound contrasts and to categorize allophonic sound contrasts as belonging to the same category, the former signaling a contrast in linguistic form (e.g. different words), the latter signaling variations of the same form (e.g. different variations of the same word). Infants adapt their categorical perception of speech sounds to the phoneme inventory of their native language during the first year of life (Kuhl, Williams, Lacerda, Stevens, \& Lindblom, 1992), however, one’s categorical perception of speech sounds is to some extent malleable well into adulthood when e.g. acquiring a foreign language (A. H. Nielsen, Horn, Sørensen, McGregor, \& Wallentin, 2015).

This heightened sensitivity to certain sound contrasts over others that characterizes categorical speech perception has been correlated with a well-studied component of the auditory event-related potential (ERP/ERF), namely the mismatch negativity $(\mathrm{MMN})$ and its magnetic counterpart (MMNm) (for reviews see Kujala, Tervaniemi, \& Schröger, 2007; Näätänen, Paavilainen, Rinne, \& Alho, 2007; Shtyrov \& Pulvermüller, 2007). Native phonemic contrasts have been shown to elicit larger or earlier MMN responses than comparable non-native or non-phonemic ones (Chládková, Escudero, \& Lipski, 2013; Dehaene-Lambertz, 1997; DehaeneLambertz, Dupoux, \& Gout, 2000; Kazanina, Phillips, \& Idsardi, 2006; Kirmse et al., 2007; Miglietta, Grimaldi, \& Calabrese, 2013; Näätänen et al., 1997; Noordenbos, Segers, Serniclaes, \& Verhoeven, 2013; Phillips et al., 2000; Sharma \& Dorman, 2000; Winkler, Kujala, et al., 1999a; Winkler, Lehtokoski, et al., 1999b; Ylinen, Shestakova, Huotilainen, Alku, \& Näätänen, 2006). The most widely adopted explanation for this increased MMN to familiar phonemic contrasts is that there exist 
long-term memory traces for sounds specific to one's native language, mainly in the left superior temporal lobe (Alho et al., 1998; Dehaene-Lambertz, 2000; Koyama et al., 2000; Näätänen et al., 1997; Rinne et al., 1999; Shestakova et al., 2002; Shtyrov et al., 1998; Shtyrov, Kujala, Lyytinen, Ilmoniemi, \& Näätänen, 2000), proposed to function in parallel with the short-term memory traces driving the more purely acoustic MMN (Näätänen, Gaillard, \& Mäntysalo, 1978).

However, some phonemic contrasts may be neutralized in certain phonetic contexts of a given language, such as word-finally in e.g. German (Iverson, 2008; Vaux \& Samuels, 2006) and Danish (Basbøll, 2005). How do such phonological processes influence the effect of the proposed long-term memory traces for speech sounds on the MMN? If these memory traces are sensitive to the phonemic contrasts of one's native language, are they also sensitive to neutralizations of such contrasts in certain phonetic contexts?

Within a different strand of research, but still related to allophonic and phonemic representations, Lahiri \& Reetz $(2002 ; 2010)$ have put forth a theoretical framework for a Featurally Underspecified Lexicon (FUL), building on the notion that the underspecification of certain phonological features leads to more efficient lexical processing. This is exemplified by the place of articulation feature [coronal], which they propose to be underspecified in e.g. English compared to [labial] or [velar]. Hence, /n/ assimilates to [m] when followed by a [+labial] sound, whereas $/ \mathrm{m} /$ does not assimilate or only rarely assimilates to [n] when followed by a [+coronal] sound; compare "lea $[m]$ bacon" (instead of "lea[n] bacon") with "la[m]e duck" (and not "la[n]e duck") (examples are from Lahiri \& Reetz, 2002; Scharinger, Bendixen, Trujillo-Barreto, \& Obleser, 2012a). Using the MMN to probe predictions from the 
FUL framework, several studies have found asymmetries in the MMN to English, German and Dutch stimuli in support of certain underspecified phonological features (Cornell, Lahiri, \& Eulitz, 2011; 2013; Cummings, Madden, \& Hefta, 2017; Diesch \& Luce, 1997; Eulitz \& Lahiri, 2004; Hestvik \& Durvasula, 2016; Scharinger et al., 2012a; Scharinger, Lahiri, \& Eulitz, 2010; Schluter, Politzer-Ahles, \& Almeida, 2016; Walter \& Hacquard, 2004). However, Scharinger et al. (2011) reported nonsupportive findings, Tavabi et al. (2009) only found partially supportive effects, and Bonte et al. (2005) found evidence of a phonotactic effect rather than of underspecification.

In this context, Danish phonology offers an interesting case for investigating potential underspecification effects and phonetic context effects on the MMNm response to native speech sounds. In Danish, plosives differ phonemically in place of articulation [labial, coronal, velar] and in degree of aspiration [+/-spread glottis] (Basbøll, 2005). Hence, the alveolar plosives $/ \mathrm{t} /$ and $/ \mathrm{d} /$ contrast between aspirated $[+\mathrm{spread}]$ and voiceless, unaspirated [-spread] ${ }^{1}$, respectively. However, aspiration of the plosives is weakened, and thus voice-onset-time (VOT) is reduced to $\sim 0-10 \mathrm{~ms}$ in several phonetic contexts in Danish (mainly word- and syllable-finally) whereby the contrasts between the aspirated $/ \mathrm{p} \mathrm{t} \mathrm{k/} \mathrm{and} \mathrm{the} \mathrm{voiceless,} \mathrm{unaspirated} / \mathrm{b} \mathrm{d} \mathrm{g/are} \mathrm{neutralized}$ (Basbøll, 2005). To those unfamiliar with Danish phonology, referring to /b d g/ as voiceless and unaspirated may seem somewhat counterintuitive, but this is customary for the Danish plosive contrasts and corresponds with the phonetic reality (Basbøll, 2005; Grønnum, 2005).

\footnotetext{
${ }^{1}$ Aspiration for the alveolar plosive is realized as affrication in Danish, hence the phonetic realizations of the $/ \mathrm{t} d /$ contrast are more precisely denoted as affricated $\left[\mathrm{t}^{\mathrm{s}}\right]$ vs. voiceless, unaffricated [d] (all other phonetic transcriptions in this paper are broad transcriptions, and we will thus refer to the contrast simply as between [t] and $[\mathrm{d}]$ ).
} 
This means that [ta] and [da] form different words in Danish (meaning "take" and "then", respectively) whereas [at] and [ad] are different realizations of the same word /at/ (meaning "that" in Danish). Both [at] and [ad] occur in casual Danish speech where $[\mathrm{ad}]$ is the, by far, most common realization, and [at] mainly appears in emphatic or hesitant contexts (e.g. before longer pauses, see Discussion for more details on their relative frequencies) (Basbøll, 2005).

To the best of our knowledge, the potential underspecification of [spread glottis] has not been investigated within the FUL framework. But we may hypothesize that [spread] could be underspecified (at least in Danish), since, as already stated, the neutralization pattern holds for all plosive contrasts in Danish, and thus, hearing [b], [d] and [g] syllable-finally in Danish does not mismatch with a possible /p/, /t/ and /k/, respectively, in the lexical representation (so-called no-mismatch in FUL), whereas hearing $[\mathrm{p}]$, [t] and [k] syllable-finally does mismatch with a possible /b/, /d/ and /g/ (so-called mismatch in FUL). FUL generally predicts that a given feature is underspecified regardless of phonetic context because the matching process happens at the lexical representational level (Lahiri \& Reetz, 2010). We therefore hypothesized that hearing [t] as a deviant against [d] as a standard would elicit a stronger MMNm than hearing [d] as a deviant against [t] as a standard. This would be so because the predicted underspecified [spread] feature of the standard in the latter leads to a less specific and less precise representation of the standards against which the $[\mathrm{d}]$ as deviant only causes a minor mismatch, if any.

For the potential effect of the phonetic context on the MMNm to the phonological contrasts between $/ \mathrm{t} /$ and $/ \mathrm{d} /$, we hypothesized that if the long-term memory traces are sensitive to the neutralization of such contrasts as dictated by the phonetic context, 
then we would see a stronger MMNm to the phonological contrast between /t/ and /d/ when presented word-initially in [ta] and [da] than when presented word-finally in [at] and [ad].

Finally, in order to further substantiate our neurobiological investigations, we conducted a second experiment testing a different (slightly overlapping) group of native Danish listeners on their behavioral discrimination sensitivity to the two stops in the two phonetic contexts, using a behavioral oddball design similar to that used by Scharinger et al. (2012a).

\section{Methods}

\section{Experiment 1 (MEG): MMNm responses}

\section{Participants}

Eighteen volunteers (nine women) participated in the study. One participant's data was discarded due to technical problems with the signals from the head-positionindicators (HPIs). The mean age of the remaining 17 participants (nine women) was 26.4 years $(\mathrm{SD}=4.8)$. All were native Danish listeners (all reporting substantial experience with 2-3 foreign languages, English being their primary second language, except for one participant whose primary L2 was Vietnamese). All reported having normal hearing, and none reported any history of neurological or psychiatric illness.

Gender differences were not deemed important (Wallentin, 2009; Wallentin, Michaelsen, Rynne, \& Nielsen, 2014).

The investigation was approved by the local ethics committee (De Videnskabsetiske Komitéer for Region Midtjylland) and thus in accordance with the Declaration of Helsinki. Written consent was obtained from each participant. 


\section{Stimuli}

Auditory stimuli were centered around the Danish $[\mathrm{t}]-[\mathrm{d}]$ contrast (aspirated versus unvoiced), which is phonemic syllable-initially, but allophonic syllable-finally (Basbøll, 2005). The target stimuli were four Danish syllables: [ta] (running speech realization of 'take'), [da] (meaning 'then'), and [at] and [ad] (both are realizations of the complementizer 'that' or the infinitive marker 'to'). Relevant syllables were recorded by a male native Danish speaker (the first author), and the stimuli were then created by cross-splicing the sounds so that the same vowel [a] was used for all syllables, and the same [t] and [d] were each used for the two relevant syllables ([ta] and [at], and [da] and [ad], respectively, figure 1B), a process similar to that used by Shtyrov et al. (2002; 2005).

The vowel [a] used in all four stimuli was 95 ms long; [t] used in both [ta] and [at] was $74 \mathrm{~ms}$ long; and [d] used in both [da] and [ad] was $24 \mathrm{~ms}$ long (figure 1B). The total durations of the sounds were thus $169 \mathrm{~ms}$ for [ta] and [at], and $119 \mathrm{~ms}$ for [da] and [ad]. Since vowel duration is phonemic in Danish (Basbøll, 2005; Grønnum, 2005), the vowels in [da] and [ad] were not prolonged in order to match the total durations of [ta] and [at]. The initial and final $5 \mathrm{~ms}$ of each sound were used for fadein and fade-out. The stimuli were finally validated by two native Danish listeners, naïve to the design of the experiment.

Analysis of the sounds prior to editing was done using Praat (Boersma \& Weenink, 2013). All recording and editing was done using Audacity (http://audacity.sourceforge.net/). 
A

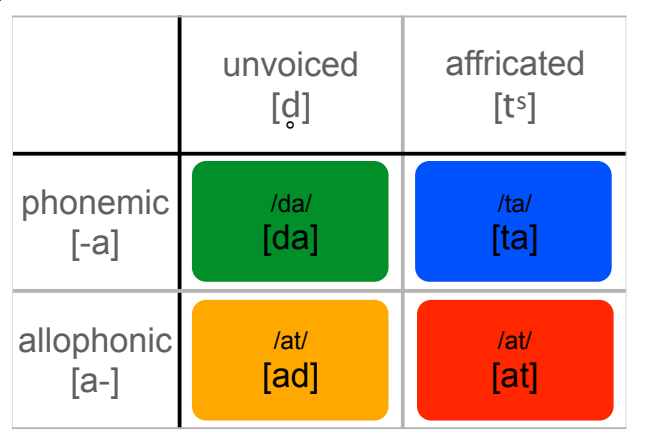

B

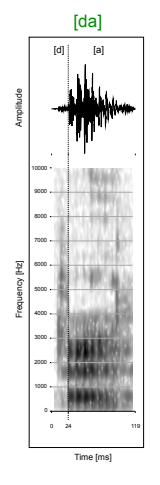

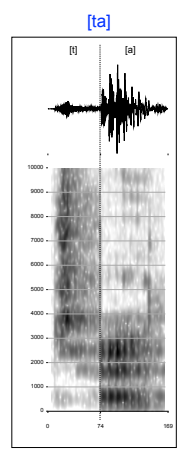
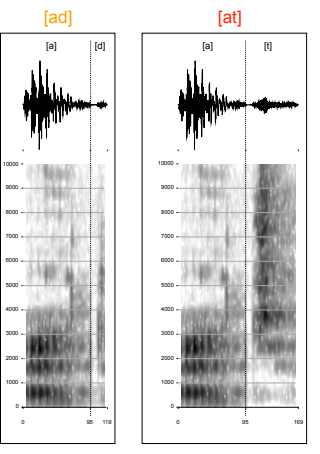

C
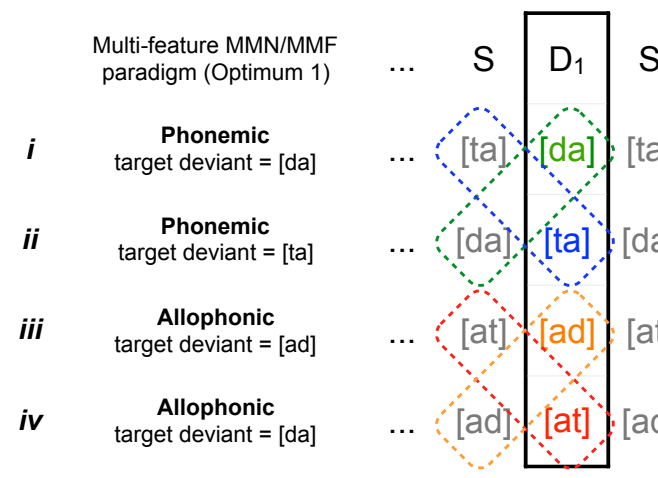

$\mathrm{S} \quad \mathrm{D}_{2}$

$\mathrm{S} \quad \mathrm{D}_{3}$

[te] [ta] [at] [ta] [TA $\ldots$

[da] [de] [da] [ad] [da] [DA] $\ldots$

[at] [et] [at] [ta] [at] [AT] $\ldots$

Figure 1. (A) The experimental design was a $2 \times 2$ factorial design with Context ([a-] vs. [-a]) and Phoneme ([t] vs. [d]) as factors. (B) Spectrograms and amplitudes of the four target stimuli: [ta], [da], [at], and [ad]. The same [a]-vowel (95 ms duration) was used in all four stimuli. See the text for more details on the recording and design of the stimuli. (C) Examples of the multi-feature MMN paradigm for each of the four conditions. Standard sounds as every second sound, and deviant sounds as every other alternate sound. The deviants were presented in pseudo-random order so that the routine of four deviants was always repeated with a different order. The four target deviants (here $\mathrm{D}_{1}$ ) are highlighted by the vertical box. The diagonal and truncated squares illustrate that the MMNm was calculated by subtracting the ERFs to the standards and deviants of the same sound (so-called identity difference waves). The colors refer to the colors of the ERF-plots in the subsequent figures.

\section{Procedure}

Participants were seated in a magnetically shielded and sound-attenuated room. They received the auditory stimuli via in-ear headphones (Etymotic ER•30), at a comfortable hearing level of approximately $70 \mathrm{~dB}$. The presentation of the stimuli was controlled and executed by Presentation software (Neurobehavioral Systems, 
Inc., Albany, CA, USA). The participants watched a set of silent short films while instructed not to attend to the auditory stimuli playing in the headphones.

This experiment consisted of four conditions, allowing for a direct comparison of the individual stimuli: two phonemic word-initial conditions with [ta] and [da] as both deviant and standard in reversed roles; and two allophonic word-final conditions with [at] and [ad] as both deviant and standard in reversed roles. The four conditions were all linguistic multi-feature paradigms, similar to that used by Pakarinen et al. (2007). Each condition also included three "filler" deviants: one differing in vowel: [te], [de], [et] and [ed]; one in syllable-structure: [at], [ad], [ta] and [da]; and one in intensity: $[\mathrm{ta}]+6 \mathrm{~dB},[\mathrm{da}]+6 \mathrm{~dB},[\mathrm{at}]+6 \mathrm{~dB}$, and $[\mathrm{ad}]+6 \mathrm{~dB}$. These were included in an attempt to develop a linguistic multi-feature paradigm in Danish that could also contain short multi-word semantic/syntactic/prosodic units. However, discussion of this matter is not within the scope of this paper and will be reported elsewhere.

The inclusion of all four conditions in the experimental design allowed for a direct comparison of each of the four target stimuli, [ta], [da], [at] and [ad], as both deviant and standard, thus controlling for exogenous effects of the stimuli (Kujala et al., 2007). And furthermore, it allowed for a 2 x 2 factorial design in which the potential effects of both context (syllable-initial vs. syllable-final) and direction of contrast ([d] among $[\mathrm{t}]$ vs. $[\mathrm{t}]$ among $[\mathrm{d}]$ ) could be tested (figure $1 \mathrm{~A}, \mathrm{C}$ ).

In a multi-feature MMN paradigm the standard stimulus (here: [ta], [da], [at], or [ad]) is presented as every second sound, and the four deviants (here consisting of consonant, vowel, syllable structure and intensity variations) are then presented in pseudo-random order as every other alternate sound (figure 1C). The pseudorandomization ensured that all four deviants were presented before the routine was 
repeated with a different order (similar to Näätänen, Pakarinen, Rinne, \& Takegata, 2004; Pakarinen et al., 2009). Each deviant was presented a total of 120 times. The inter-stimulus-interval (ISI) was jittered between $180 \mathrm{~ms}$ and $480 \mathrm{~ms}$ (mean $330 \mathrm{~ms}$ ). Each condition consisted of two blocks of approx. 4 min duration (i.e., 480 stimuli per block, totaling 960). The order of the $4 \times 2$ blocks was counter-balanced across participants, and identical blocks were never presented back to back. Participants were given a small break between each of the 8 blocks, leading to a total duration of the experiment of approx. $40 \mathrm{~min}$.

\section{Recording and preprocessing of MEG data}

All MEG data were collected at the MEG Unit, MINDLab Core Experimental Facility, Aarhus University, using an Elekta Neuromag TRIUX MEG system with 204 planar gradiometers and 102 magnetometers. The data were sampled at $1000 \mathrm{~Hz}$ (0.1-330 Hz). Each participant's head position in the MEG system was continuously recorded using five head coils. Bipolar recordings of vertical and horizontal eye movements were obtained using surface electrodes placed above and below the left eye and at the outer canthi of both eyes, respectively.

Data were pre-processed using the temporal extension of the signal source separation (tSSS) technique (Taulu \& Simola, 2006; Taulu, Kajola, \& Simola, 2004) using Elekta's MaxFilter software (Version 2.2.15). This included removing head-externally generated electromagnetic sources, and compensating for head movements using continuously recorded head position indicators (cHPI). Next, data were band-pass filtered at 0.8-40 Hz using MNE-Python (Gramfort et al., 2013; 2014), and eye-blinks were removed using independent component analysis (ica) and the find_bads_eog detection algorithm in MNE-Python where detection of eye blinks is based on a 
combination of Pearson's correlations between vertical/horizontal EOG and the independent components of the data. The topographies of the identified eye blink components and the averaged epochs of these components around identified peaks in the EOG were subsequently visually inspected for any inconsistencies in the eye blink component detection, and we did not find any such.

All subsequent preprocessing steps were conducted using SPM8 (Welcome Department of Cognitive Neurology, London, UK; see Litvak et al. (2011)). Data were epoched around deviance onset instead of stimulus onset in order to compare brain responses time-locked to the onsets of the target sounds [d] and [t] (see figure 3). Stimulus onset and deviance onsets differed for the two allophonic conditions ([ad] and [at]) relative to the two phonemic conditions ([da] and [ta]), thus epoching was shifted $95 \mathrm{~ms}$ (equal to the duration of [a]) later for the former two conditions. Time after deviance onset included in the epoching was $400 \mathrm{~ms}$.

Baseline-correction was conducted using the pre-stimulus interval of $100 \mathrm{~ms}$, and not the pre-deviance interval of $100 \mathrm{~ms}$, which would otherwise have included the responses to the initial [a]-sound in the allophonic condition (see figure 3). Further artifact rejection was conducted using first thresholding and then robust averaging (Litvak et al., 2011; Wager, Keller, Lacey, \& Jonides, 2005). Thresholding was done using peak-to-peak thresholds of 8 pT for magnetometers; $200 \mathrm{pT} / \mathrm{m}$ for planar gradiometers; and $300 \mu \mathrm{V}$ for EOG. The $300 \mu \mathrm{V}$ threshold for the EOG channels is a common level for the Neuromag TRIUX MEG system and does not compare well to levels used with EEG/EOG data recorded using an EEG-only amplifier. Because robust averaging may induce high frequency artifacts in the data, the epochs were after averaging again low-pass filtered at $40 \mathrm{~Hz}$ and baseline-corrected (again with 
reference to the pre-stimulus interval of $-100 \mathrm{~ms}$ to stimulus onset). Mean number trials passed through to averaging after applying the above-mentioned thresholds was for the four standard stimuli 433 trials ( $\mathrm{SD}=1.9$ across the four standards, and $\mathrm{SD}=52.3$ across participants) out of 480 standard trials per condition; and for the four times four deviant stimuli, 108 trials $(\mathrm{SD}=0.8$ across the 16 deviants, and $\mathrm{SD}=12.9$ across participants) out of 120 deviant trials were passed through to averaging; for both standards and deviants equivalent to $\sim 90 \%$ of the total number of trials.

We computed the relevant difference waves by subtracting each participant's ERF to the standard version of any given stimulus (e.g. [ta]) from their ERF to the deviant version of that very same stimulus (e.g. [ta]), thus contrasting participants' neural responses to acoustically identical stimuli. The four difference waves for each participant were then finally cropped so that only the epoched time windows from deviance onset to $400 \mathrm{~ms}$ after deviance onset (thus leaving out the baseline) were passed on to the subsequent statistical analyses.

\section{Statistical analyses}

For statistical analyses of the MEG data, we focused on the magnetometer data. In order to identify significant differences within and between the four conditions, we analyzed the difference waves from the four conditions at the sensor-level across temporal and spatial dimensions. All statistical analyses were conducted using SPM12b (v5642). The resulting $F$-maps from the statistical tests were for each test visually compared to the full channel overlays of the group-averaged ERFs to the relevant standard and deviant sound. This was done in order to ensure that the effects identified by the statistical tests corresponded to the typical topographical characterizations of the MMNm in magnetometers, viz. a bipolar anterior-posterior 
field pattern over either hemisphere consistent with an inferred underlying dipole locus in or in close vicinity of the auditory cortex in the superior temporal gyrus (Alho et al., 1996; Hari et al., 1984; Phillips et al., 2000; Shtyrov et al., 2012; Tiitinen, May, Reinikainen, \& Näätänen, 1994).

This entailed first modeling each of the four contrasts individually using two-tailed one-sample t-tests in the GLM framework of SPM in order to test whether the four conditions elicited detectable MMNms. Next, in order to test for main effects of context and perceptual asymmetry, we modeled each of the four averaged conditions in a flexible factorial design with the two factors of interest Context (2 levels: phonemic and allophonic), and Phoneme (2 levels: [t], [d]). Furthermore, a Subject (17 levels) factor was included in order to model the subject-specific variance inherent to within-subjects designs.

To this end, we first re-arranged the data into a suitable format. We created threedimensional volumes for each of the four ERF difference waves (these volumes included all channels and the full time span of the ERF post deviance onset, i.e., from 0 to $400 \mathrm{~ms}$ ). We did this by first projecting each participant's preprocessed and averaged data onto a 2D image (64 x 64 pixels) of the sensor-array for each sample in the epoch (i.e., time occupying the third dimension). This resulted in a 3D-volume (space [left-right] x space [front-back] x time) for each participant for each difference wave for each condition (two phonemic and two allophonic). For an informative illustration of this process of re-arranging the data, see the lower panel of Fig. 3 in Shtyrov et al. (Shtyrov et al., 2012:2609). Finally, all four of these 3D-volumes were smoothed with a kernel of $20 \mathrm{~mm}$ x $20 \mathrm{~mm}$ x $20 \mathrm{~ms}$ FWHM (full-width-half-max).

In each voxel of each participant's four 3D-volumes we modeled the response 
difference by our contrast of interest using either one-sample t-tests (MMNms in the individual conditions) or our flexible factorial design. This resulted in sensor spaceby-time statistical parametric maps (SPMs) of the relevant contrasts (Kilner \& Friston, 2010; Litvak et al., 2011).

For the tests of MMNms in the individual conditions, we fitted a GLM to the data in each voxel of the 3D volumes of each participant's four difference waves separately. And for the flexible factorial design, we fitted a general linear model (GLM) that included all condition and subject effects to the data in each voxel of each participant's four difference-wave-volumes. In the resulting SPMs, clusters of suprathreshold voxels (at $p_{\mathrm{UNC}}<0.001$, uncorrected) were family-wise-error corrected at $p_{\mathrm{FWE}}<0.05$ for spatial extent using random field theory (Kilner \& Friston, 2010; Worsley \& Friston, 1995). The actual extent threshold for the FWE-correction at cluster-level was queried using the CorrClusTh script, provided by Thomas Nichols (http://www-personal.umich.edu/ nichols/JG5/CorrClusTh.m).

The more classical approach of selecting an a priori spatial and/or temporal region of interest for analysis runs the risk of inflating the probability of false-positives (type II errors) (Kilner, 2013). Mass univariate statistics (such as GLM analyses), on the other hand, allow for more unbiased statistical analyses of the contrasts of interest across both spatial and temporal dimensions when combined with the appropriate corrections for multiple comparisons, e.g. using random field theory (Crowley, $\mathrm{Wu}, \mathrm{McCreary}$, Miller, \& Mayes, 2012; Kilner, 2013; Kriegeskorte, Simmons, Bellgowan, \& Baker, 2009; Lage-Castellanos, Martínez-Montes, Hernández-Cabrera, \& Galán, 2010). 


\section{Experiment 2 (behavioral): Oddball detection}

\section{Participants}

Eight participants (three women) volunteered to take part in the study. Two of these (two women) had also participated in Experiment 1. All reported Danish as their native language, and all reported having normal hearing.

\section{Stimuli}

The stimuli were exactly the same syllables as used in Experiment 1.

\section{Procedure}

Participants were seated in a quiet office temporarily employed for testing purposes. They received the auditory stimuli via in-ear headphones at a hearing level of approximately $70 \mathrm{~dB}$ and were asked to focus on a fixation cross at the center of the screen during the experimental conditions. The stimuli were presented using Presentation software (Neurobehavioral Systems, Inc., Albany, CA, USA) on a Windows partition of a MacBook Pro 15" laptop.

The experiment consisted of four multi-feature oddball conditions, exactly as in Experiment 1: one condition with [ta] as the standard, [da] as the target deviant, and [te], [at] and [ta] $+6 \mathrm{~dB}$ as filler deviants; one with [da] as the standard, [ta] as the target deviant, and the relevant filler deviants; one with [at] as the standard, [ad] as the target deviant, and the relevant filler deviants; and one with [ad] as the standard, [at] as the target deviant, and the relevant filler deviants. The multi-feature oddball paradigms were the same as those used in Experiment 1, except that the number of presentations of each deviant was 20 for each condition, and the ISI was varied between 600 and $900 \mathrm{~ms}$ in order to allow participants more time to respond. 
Participants were instructed to make speedy responses using the space bar whenever they detected a target deviant.

The order of the four conditions was randomized across participants. Each condition was preceded by an exposure to the target deviant and a practice session. The exposure consisted of three repetitions of the target deviant with an ISI of $750 \mathrm{~ms}$. Participants were instructed that the sound playing in their ears during the exposure would be their target sound in that condition. We referred to the syllables as 'sounds' in order not to confound the experiment by the use of the concept of a 'word'. (The reader is reminded that [ta] and [da] represent two different words in Danish, whereas [at] and [ad] are different phonetic realizations of the same word.) The practice session consisted of one or two practice runs of the experiment with three target deviant presentations (in a total of 24 trials). If participants achieved two or more hits (out of three possible) and less than five false alarms, they were given the option of proceeding to the real experiment or trying one more practice session. One participant received the instructions an extra time after twice failing to meet the criteria during the first condition.

\section{Statistical analyses}

For the statistical analyses, we considered responses between $210-1110 \mathrm{~ms}$. This interval was based on the distribution of responses by identifying the longest gap between response times in the 0-300 ms time window, which was between 207 and $285 \mathrm{~ms}$ (see Supplementary materials, figure S1). Responses given during the first $210 \mathrm{~ms}$ of the following sound, which where thus treated as belonging to the preceding trial, accounted for $4.3 \%$ of the total amount of responses, and these were mainly ( $\sim 89 \%)$ given to trials with an ISI below the mean ISI of $750 \mathrm{~ms}$. This 
correction was particularly important in order not to bias the results in favor of the [t]oddballs (since these sounds were longer than the [d]-oddballs, and would thus have given participants, on average, $50 \mathrm{~ms}$ longer response times).

We used participants' discrimination sensitivity as indexed by their d-prime (d') values as our dependent measure. We calculated participants' $d$ ' values by subtracting their standardized (z-value) false alarm rate from the $z$-value of their hit rate (Macmillan \& Creelman, 2005). False alarm rates were based on all non-target stimuli, i.e., both standards and filler deviants of the multi-feature MMN paradigm. Because $z$-values approach infinity for response rates of $0 \%$ and $100 \%$ these were corrected by + and $-1 /(2 * N)$, respectively (Macmillan \& Creelman, 2005), where $\mathrm{N}$ is the number of observations that the given rate was calculated on, hence 140 for the false alarm rate ( 80 standards +60 filler deviants) and 20 for the hit rate (20 target deviants) for each condition.

In order to test for both main and interaction effects of our factorial design, we conducted a repeated measures ANOVA with Context and Phoneme as withinsubjects factors (using the repanova.m function in MATLAB, http://www.mrccbu.cam.ac.uk/people/rik.henson/personal/analysis/).

\section{Results}

\section{Experiment 1 (MEG): MMNm responses}

The participants' grand-averaged ERFs to both the standard and deviant versions of the four target deviants ([da], [ta], [ad], and [at]) are presented as full channel overviews in the supplementary material (figure S2). In figure 2, grand-averaged ERFs for the standards and deviants of all four conditions are presented together. 
These ERFs are averages of eight left-posterior sensors (top row) and eight rightposterior sensors (middle row). The selection of sensors was based on the largest M100-fields (defined as averages of 75-125 ms after sound onset) to both standards and target deviants in all four conditions (see Kazanina et al., 2006 for a similar selection criterion). For each condition, the topographies of the difference waves are shown for averaged intervals of $100-170 \mathrm{~ms}, 170-240 \mathrm{~ms}, 240-310 \mathrm{~ms}$, and $310-380$ ms (bottom row) in order to further substantiate the differences observed in the standard and deviant ERFs with typical MMNm topographies wherever relevant. The statistical analyses of the $\mathrm{MMNm}$ in each of the four condition are presented in figure $3 \mathrm{~A}-\mathrm{D}$ (for full reporting, thresholds are set to $p_{\mathrm{UNC}}<0.001$ ) together with the results of the factorial analysis in figure 3E (see the supplementary material, tables S1 and S2, for further details on the SPM statistics, as well as figure S3 for statistical maps with $p_{\mathrm{FWE}}<0.05$ thresholds).
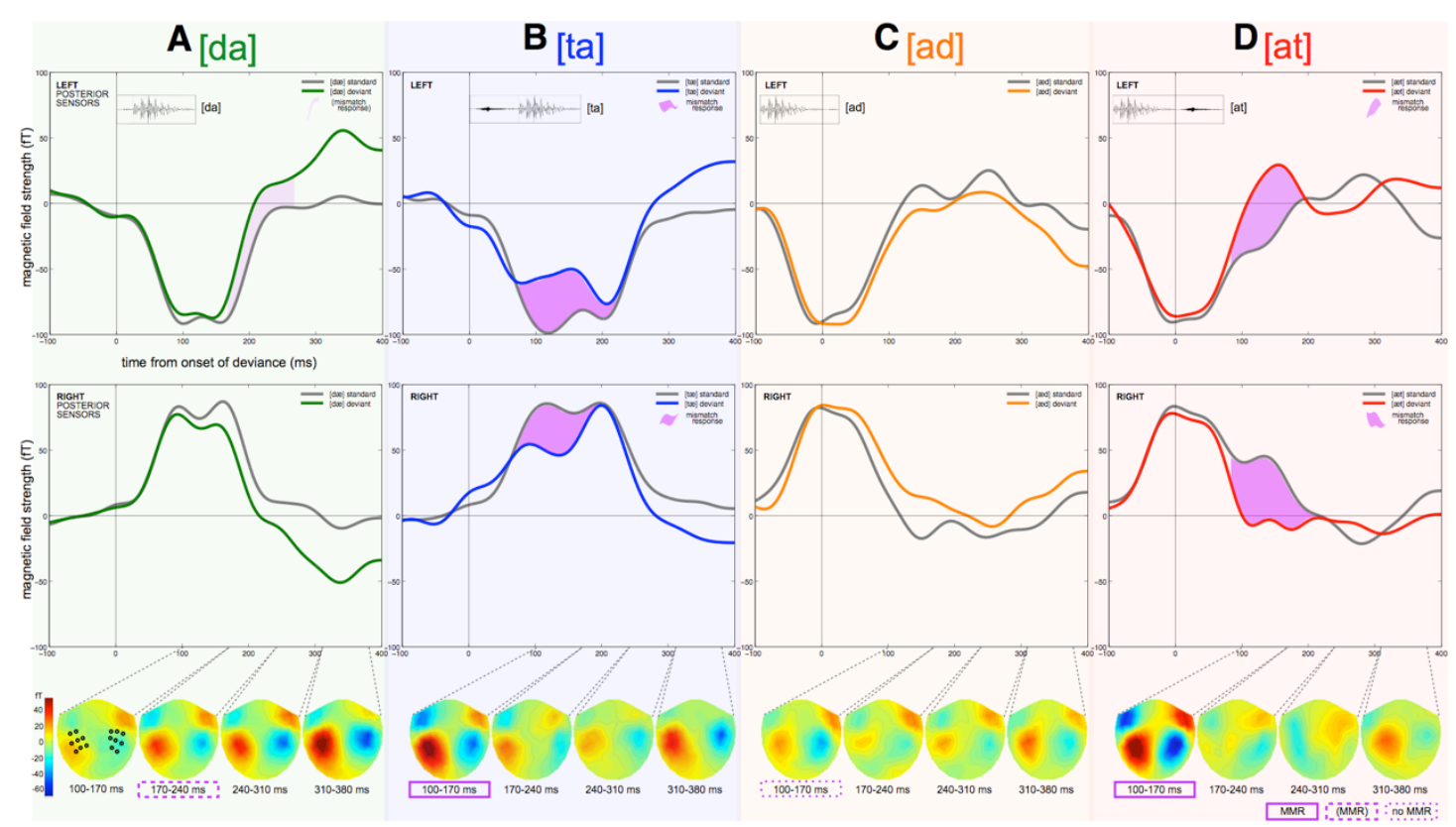

Figure 2. Grand-averaged ERFs to the standard and deviant sounds of all four conditions (A: [da]; B: [ta]; C: [ad]; D: [at]). Averages of eight peak sensors at the left posterior site (top row) and eight peak sensors at the right posterior site (middle row). These sensors were selected on the basis of the largest M100-fields (averaged 
from 75-125 ms after sound onset) across standards and target deviants in all four conditions. The amplitudes of the relevant stimulus for each condition illustrate the epoching of the ERFs around deviance onset. Bottom row: For each condition, topographies of the relevant difference waves are shown as averages of four intervals: 100-170 ms after deviance onset, 170-240 ms, 240-310 ms, and 310-380 ms, where only the last interval is outside the typical temporal range for an MMN (i.e., 100-300 ms after deviance onset). A solid purple box around the time interval indicates an MMNm topography overlapping with the statistical analyses (see figure 3); a truncated purple box indicates an MMNm topography that passed the uncorrected, but not the FWE-corrected, statistical threshold; a dotted purple box indicates a weak MMNm topography that did not pass any statistical thresholds.

\section{[d] (phonemic condition)}

The phonemic condition with [da] as the target deviant (presented against [ta] as the standards) elicited MMNm-like bipolar field pattern differences in the 170-240 ms range (figure $2 \mathrm{~A}$ ). This was somewhat later than for [ta] and [at] as target deviants (see “ $[\mathrm{t}]$ (phonemic condition)" and “ $[\mathrm{t}]$ (allophonic condition)" below), where the MMNm appeared in the $100-170 \mathrm{~ms}$ range. A cluster over the left posterior (LP) lateral sensors with a temporal extent of $179-216$ ms almost passed the $p_{\mathrm{FWE}}<0.05$ threshold for extent (LP: $k=6050, p_{\mathrm{FWE}}=0.057$, where $k$ is the number of voxels in the cluster and $p_{\text {FWE }}$ refers to the cluster-statistics, see figure $3 \mathrm{~A}$ and table $\mathrm{S} 1$ ).

Furthermore, a late effect was elicited in the SPM analyses around 290-365 ms, which revealed significant clusters over left posterior (LP) and right posterior (RP) lateral sensors (LP: $k=34610, p_{\mathrm{FWE}}<0.001$; and RP: $k=15745, p_{\mathrm{FWE}}=0.003$, figure $3 \mathrm{~A}$ and table S1). This effect overlapped with a strong field pattern complex in the 310-380 ms range. However, this latency was outside the typical MMN-range (100-300 ms), and yet the scalp topography (of which both left and right posterior fields overlapped with the SPMs) was somewhat similar to the MMNm in the [ta] and [at] conditions in 
the $100-170 \mathrm{~ms}$ range (figure 2B,D), as well as the MMNm-like effect that nearly passed the $p_{\mathrm{FWE}}<0.05$ threshold for extent in this very same condition in the $170-240$ ms range $\left(k=6050, p_{\mathrm{FWE}}=0.057\right.$, figure $3 \mathrm{~A}$ and table $\mathrm{S} 1$ (in grey) $)$. The butterfly-plot of the difference wave in all the channels in figure $3 \mathrm{~A}$, upper right quadrant, confirms two distinct peaks: one in the 170-240 ms range, and another one peaking in the 310 $380 \mathrm{~ms}$ range.

\section{[t] (phonemic condition)}

The phonemic condition with [ta] as the target deviant (presented against [da] as the standard) elicited significant clusters over left anterior (LA), left posterior (LP), and right posterior (RP) lateral sensors with a temporal extent of 97-164 ms (LA: $k=7973$, $p_{\mathrm{FWE}}=0.037$; LP: $k=26793, p_{\mathrm{FWE}}<0.001$; and RP: $k=7581, p_{\mathrm{FWE}}=0.041$; figure $3 \mathrm{~B}$ and table S1), all overlapping with the clear MMNm-like bipolar field pattern differences over both hemispheres in the 100-170 ms range after deviance onset (figure 2B).

\section{[d] (allophonic condition)}

The allophonic condition with [ad] as the target deviant (presented against [at] as the standard) did not elicit any clusters that survived the $p_{\mathrm{FWE}}<0.05$ threshold for extent (figure $3 \mathrm{C}$ ). At the $p_{\mathrm{UNC}}<0.001$ threshold for height, there were traces of effects over right anterior and right posterior lateral sensors, and the butterfly-plot of the difference wave in all the channels (figure 3C, upper right quadrant) shows vague indications of a peak in the 100-170 ms range together with only a very weak MMNm-like topography in the 100-170 ms range (figure 2C), and as already stated, none of these weak indications were mirrored in statistically significant effects from other conditions. 


\section{[t] (allophonic condition)}

The allophonic condition with [at] as the target deviant (presented against [ad] as the standard) revealed significant clusters over left posterior (LP) and right posterior (RP) lateral sensors with a temporal extent of $106-167 \mathrm{~ms}\left(\mathrm{LP}: k=18781, p_{\mathrm{FWE}}=0.002\right.$; and RP: $k=19796, p_{\mathrm{FWE}}=0.001$; figure $3 \mathrm{D}$ and table $\mathrm{S} 1$ ), both of which overlapped with the two posterior field patterns of the clear MMNm-like bipolar field pattern differences over both hemispheres in the 100-170 ms range after deviance onset (figure 2D).

A (later MMR) to [da]

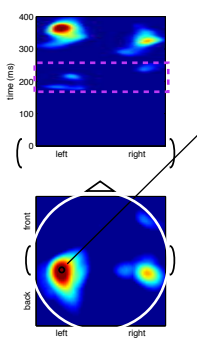

\section{C no MMR to [ad]}

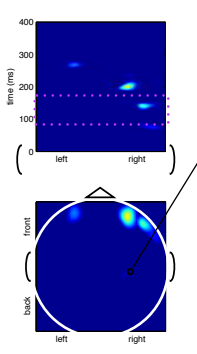

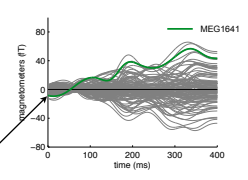
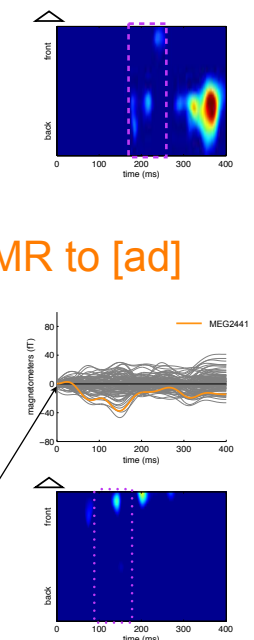

B $\quad$ MMR to $[\mathrm{ta}]$
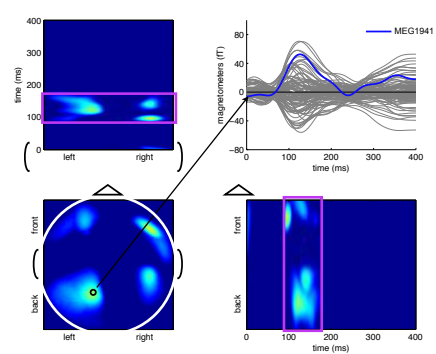

D $\quad$ MMR to [at]

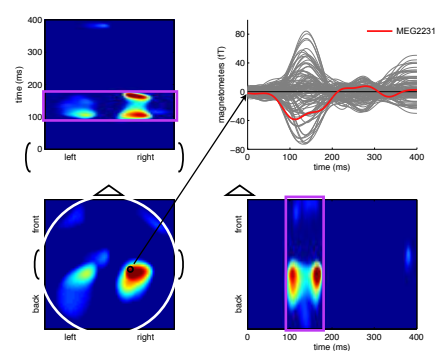

E Main effect of Phoneme
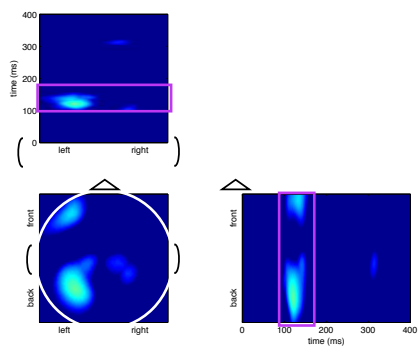

at $p_{U N C}<0.001$ :

$$
\begin{array}{|c|c}
\hline \text { MMR } & \sim 100-170 \mathrm{~ms} \\
\hdashline \text { (MMR) } & \sim 170-240 \mathrm{~ms} \\
\hdashline \text { no MMR } & \sim 100-170 \mathrm{~ms} \\
\hline
\end{array}
$$

Figure 3. Statistical parametric maps (SPMs) of the difference waves from each of the four conditions (A: [da]; B: [ta]; C: [ad]; D: [at]), as well as the only main effect from the flexible factorial analysis showing significant effects (E: main effect of Phoneme). See the text for more details on the computation of the SPMs and the designs of the contrasts for the individual conditions and the flexible factorial analysis. The SPMs are thresholded at $p_{\mathrm{UNC}}<0.001$ (for height) for full reporting. See Supplementary material (Figure S6) for the same SPMs thresholded at $p_{\mathrm{FWE}}<0.05$ (for extent). Warmer colors mean higher F-values. For each four quadrants, the lower left 
quadrant shows the max F-values of the SPM for the 2D sensor space projected onto a 64 x 64 pixel array, irrespective of time $(0-400 \mathrm{~ms})$. The upper left quadrant shows the max F-values of the SPM for the left-right axis of the 2D sensor array with time (0-400 ms) on the y-axis, hence the front-back axis is collapsed. The lower right quadrant shows the max F-values of the SPM for the front-back axis of the 2D sensor array with time $(0-400 \mathrm{~ms})$ on the $\mathrm{x}$-axis, hence the left-right axis is collapsed. The upper right quadrant shows the difference wave ERFs for all magnetometers with the ERF from the peak sensor of the most MMNm-typical effect plotted on top in the condition-relevant color. See caption for figure 2 for details on the criteria for the purple boxes.

\section{Factorial design with Context and Phoneme}

The main effect of Context did not reveal any clusters surviving the FWE-correction at $p_{\mathrm{FWE}}<0.05$, nor any noteworthy effects at $p_{\mathrm{UNC}}<0.001$. Hence, we could not find support for the Context hypothesis that the [da] and [ta] contrasts should elicit systematically stronger MMNm responses compared to the [ad] and [at] contrasts (table S2).

The main effect of Phoneme, on the other hand, revealed two clusters of consistent differences in the participants' neural responses to the [ta] and [at] contrasts compared to the $[\mathrm{da}]$ and $[\mathrm{ad}]$ contrasts. These clusters were located over the left anterior (LA) and left posterior (LP) lateral sensors (LA: $k=18410, p_{\mathrm{FWE}}=0.004$; and LP: $k=25918$, $p_{\mathrm{FWE}}=0.001$; figure $3 \mathrm{E}$ and table $\mathrm{S} 2$ ), and they overlapped with the left posterior and anterior field patterns in both [ta] and [at] contrasts (figure 2B,D).

There was no significant Context*Phoneme interaction effect.

\section{Experiment 2 (behavioral): Oddball detection}

Results of participants' discrimination sensitivities from the four conditions are 
presented in figure 4.

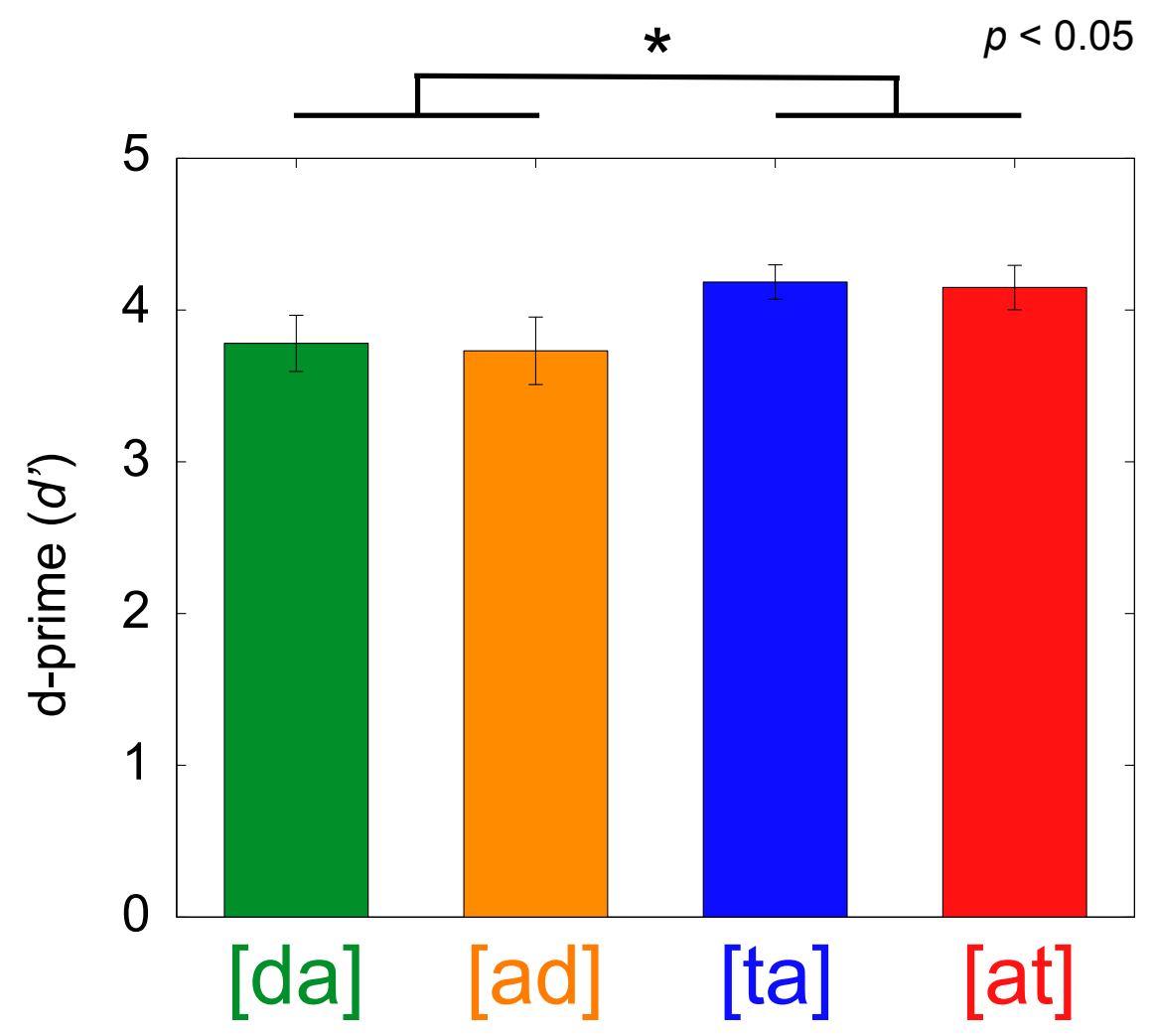

Figure 4. d-prime ( $d$ ') values from the behavioral follow-up experiment (behavioral MMN oddball task) with eight native Danish listeners. A repeated measures ANOVA with both Context and Phoneme as factors revealed only a significant main effect of Phoneme and (no interaction effects). This indicates that the participants were generally better at discriminating $[\mathrm{t}]$ as a deviant from $[\mathrm{d}]$ as a standard than at discriminating $[\mathrm{d}]$ as a deviant from $[\mathrm{t}]$ as a standard. Due to the repeated measures design, errorbars show the standard errors of the mean with across-participant differences removed (see Cousineau, 2005; Morey, 2008 for more details).

\section{Main effects and interactions}

There was no main effect of Context on participants' discrimination sensitivity as indexed by their $d$ ' values $\left(F(1,7)=0.23, p=0.64\right.$, eta $\left.^{2}=0.01\right)$. There was, however, a main effect of Phoneme on participants' discrimination sensitivity $(F(1,7)=19.73$, $\left.p=0.003, e t a^{2}=0.29\right)$, with participants' $d$ ' values, on average, being $0.48(S D=0.31)$ 
larger for the $[\mathrm{t}]$-targets than for the [d]-targets. Participants' were thus significantly more sensitive in their discrimination of the [t]-targets than of the [d]-targets. There was no significant Context*Phoneme interaction effect $(F(1,7)=0.01, p=0.93$, $\left.e t a^{2}=0.00\right)$.

The direction and significance of these results did not change if we discarded the responses from 0-210 instead of counting them as belonging to the preceding trial; this only made the main effect of Phoneme stronger.

\section{Discussion}

\section{Main findings}

In the present study we set out to investigate the potential effects of phonetic context and of asymmetries in speech perception on the human brain's passive auditory processing of language sounds. We hypothesized that a phonetic context (word-final) neutralizing the phonological contrast between $/ \mathrm{t} /$ and $/ \mathrm{d} /$ in Danish would lead to a diminished MMNm compared to a non-neutralizing context (word-initial). We did not find any support for this hypothesis in that there was no consistent effect of hearing the contrast between /t/ and /d/ either preceded or followed by the vowel /a/, respectively.

We furthermore hypothesized that [spread] may be underspecified as phonological feature of plosives in Danish, and if so, we would see an asymmetry in the MMNm to /t/ and /d/ in native Danish listeners. This hypothesis was, indeed, supported by our results which show that hearing $[\mathrm{t}]$ as a deviant with $[\mathrm{d}]$ as a standard elicited a consistently stronger MMNm than the opposite conditions (i.e., [d] as a deviant with $[\mathrm{t}]$ as a standard). And this pattern of asymmetric neuronal sensitivity was confirmed 
by a behavioral study with a group of native Danish listeners $(n=8)$ who showed significantly higher d-prime $\left(d^{\prime}\right)$ values to [t] as target oddball over [d] as target oddball.

\section{Perceptual asymmetry and the MMN}

A few other linguistic MMN studies have used stimuli similar to ours when investigating phonological effects in other languages than Danish; some directly address asymmetry and underspecification hypotheses and others only report them as bi-products of their design. Phillips et al. (2000) probed phoneme categories of native English listeners with a many-to-one design for the standards and showed a reliable MMNm to /da/ when contrasted with /ta/, but not to /ta/ when contrasted with /da/. Hence, they report indirect support for what could seem like an asymmetry in the opposite direction of what we find in Danish, however, this asymmetry effect was not explicitly tested by the authors. This was addressed by Hestvik and Durvasula (2016) who recently replicated Phillips et al.'s (2000) asymmetry findings with similar stimuli by testing the asymmetry directly, and they extended this finding by showing that the asymmetry effect disappeared when the paradigm was modified to probe phonetic memory traces of $/ \mathrm{d} /$ and $/ \mathrm{t} /$ rather than phonemic ones. Finally, Kazanina et al. (2006) used a similar experimental design to Phillips et al. (2000) when investigating /d/ and /t/ in native Russian and native Korean listeners. The contrast is only phonemic in Russian (since Korean stops contrast between plain, tense and aspirated), and only the native Russian listeners showed an MMNm to the contrast. Unfortunately, the authors collapsed the /ta/-as-deviant and /da/-as-deviant conditions without commenting on the presence or absence of any asymmetries.

In the more general MMN literature, there is no clear evidence suggesting inherent 
asymmetries in the MMN as an effect of the direction of a given contrast, rather the opposite, namely that the MMN is sensitive to the size of the change, but not the direction (Jaramillo, Paavilainen, \& Näätänen, 2000; Kaukoranta, Sams, Hari, Hämäläinen, \& Näätänen, 1989; Näätänen, 1992; Näätänen et al., 2007; Rinne, Särkkä, Degerman, Schröger, \& Alho, 2006; Ritter et al., 1992). And as such, only a few studies have reported smaller MMN amplitudes to tone deviants of shorter duration than comparable tone deviants of longer duration (Catts et al., 1995; Jaramillo, Alku, \& Paavilainen, 1999; Näätänen, Paavilainen, \& Reinikainen, 1989). Finally, Ylinen et al. (2006), reported larger MMN amplitudes to a prolonged vowel deviant than to a shortened vowel deviant, but only when the stimuli were presented within a word, not in isolation. However, both tonal and vowel stimuli are acoustically radically different from the $[\mathrm{t}]-[\mathrm{d}]$ contrast of the present study, which is perhaps most similar to the white noise burst contrasts used by Jaramillo et al. (2000) where no clear asymmetry effects were observed.

There is, however, one study that has reported very clear asymmetry effects on the MMN to more low-level auditory processing. With inspiration from Cusack \& Carlyon's (2003) seminal work on auditory pop-out effects, Bishop et al. (2005) showed a stronger MMN to frequency-modulated deviant tones among unmodulated standard tones than to unmodulated deviant tones among frequency-modulated standard tones (see also Timm, Weise, Grimm, \& Schröger, 2011 for somewhat similar results). These findings speak to the potential involvement of low-level feature detectors in perceptual asymmetry, and we therefore acknowledge that our observed asymmetry effect could, indeed, have been caused by differences in more low-level psychoacoustic processing with more broad-spectrum noise and longer duration of $[t]$ than of [d], rather than differences in the participants' phonological or lexical 
representations of the speech sounds. Further studies using closely matched nonlinguistic stimuli acoustically similar to those used in this study would be needed in order to properly tease apart psychoacoustic and psycholinguistic explanations of our observed effects.

However, since the majority of the MMN literature on non-linguistic stimuli gives inconclusive evidence for perceptual asymmetries inherent to the more general MMN. we therefore propose that the explanations put forth by the proponents of the FUL (Lahiri \& Reetz, 2002; 2010) fit our findings and the asymmetries in the linguistic MMN literature the best. In this relation, a number of studies have found support for [coronal] as an underspecified place of articulation feature in German for both plosives and vowels (Cornell et al., 2011; Eulitz \& Lahiri, 2004; Scharinger et al., 2010; 2012a), and in English for plosives and fricatives (Cummings et al., 2017; Schluter et al., 2016), and, as already mentioned, for [voice] as an underspecified laryngeal feature in English (Hestvik \& Durvasula, 2016; Phillips et al., 2000). To these findings, our present study adds an investigation of the laryngeal feature [spread] for a plosive contrast in Danish, showing an opposite pattern to that for English which seems to be in line with differences in markedness and thus specification of the [spread] feature in Danish and English. We have thus found tentative support for an asymmetric perception of aspirated and unvoiced plosives in native Danish listeners, and we take this as preliminary and relatively tentative support for [spread] as an underspecified phonological feature in Danish.

Furthermore, since [spread] as a distinctive phonological feature also applies to the contrasts between /b-p/ and /g-k/ in Danish (which also both show neutralization word-finally), we would predict on the basis of our findings that we should see 
similarly stronger $\mathrm{MMNm}$ to $[\mathrm{p}]$ than to $[\mathrm{b}]$ and to $[\mathrm{k}]$ than to $[\mathrm{g}]$. And given the amount of research into the specification of phonological representations in dyslexia (Bogliotti, Serniclaes, Messaoud-Galusi, \& Sprenger-Charolles, 2008; Elbro, 1996; Noordenbos, Segers, Serniclaes, Mitterer, \& Verhoeven, 2012; Serniclaes, Heghe, Mousty, Carré, \& Sprenger-Charolles, 2004), with both underspecification and overspecification put forth as potential explanations of the phonological deficit (Noordenbos, 2013; Noordenbos \& Serniclaes, 2015), future studies expanding on the present findings in terms of more stimuli and employing a many-to-one paradigm (as used by Hestvik \& Durvasula, 2016; Phillips et al., 2000) may allow us to better probe and understand the neurophysiology of this debilitating aspect of dyslexia.

\section{No support for a context effect}

Regarding the lack of support for an effect of phonetic context on the MMNm in the present study, one should always be careful to interpret such null results without further substantiation of said null effect, and we will therefore stress that this should not be interpreted as support for no effect of phonetic context on the MMNm. The context of the auditory scene has previously been shown by Sussman $(2007 ; 2013)$ and Sussman et al. $(2005 ; 1998 ; 2002)$ to affect MMN amplitudes to pure tones. But given that these were non-linguistic effects, they may not be directly comparable to our study.

The effect of English as a second language could potentially influence our results, given that the $[\mathrm{t}]-[\mathrm{d}]$ contrast is not neutralized syllable-finally in English (Giegerich, 1992). All subjects reported having English as their second language (except one with Vietnamese as L2, but English as L3) including at least 10 years of teaching, and selfrated proficiency scores between 7-10 on a 1-10 scale. There are, however, important 
differences between the English phonological contrast and the Danish allophonic contrast. The English contrast is partly realized syllable-finally in the vowel/consonant duration ratio (Port \& Dalby, 1982). It has shorter aspiration durations and longer closure time than in Danish (Hutters, 1985), and is affected by other factors not directly realized in the voiced-aspirated segment itself (Lisker, 1977; 1986). And hence, the realizations of the two contrasts are so different that the lack of syllable-final neutralization for this contrast in English seems unlikely to have affected the phonemic status of the contrasts in our participants' L1.

\section{Potential effects of duration and frequency}

The relatively late effect in the [da]-condition around 300-400 ms seems best explained as a duration MMNm. The durations of [da]/[ad] and [ta]/[at] were $119 \mathrm{~ms}$ and $169 \mathrm{~ms}$, respectively. It is therefore plausible that the difference in overall duration of the sounds might have elicited a subsequent MMNm of its own, timelocked to the later deviance onset (at $119 \mathrm{~ms}$ ). The temporal extent of the late MMNm in the [da]-condition was 290-365 ms relative to sound onset, which would be equivalent to 171-246 ms relative to the duration deviance onset, namely the sound offset of [da], which is within the typical temporal range of the MMN. However, we would expect such a duration MMNm to be present in the other three conditions as well (since the standard and target deviant were always of different durations). In fact, the topographies of the difference waves in figure 2 show MMNm-like topographical patterns in all four conditions in the late window $(310-380 \mathrm{~ms})$, even though only the [da]-condition showed up in the statistical analyses. Unfortunately, this experiment was not designed to tease apart potential asymmetries in the MMNm to different durations of linguistic stimuli in Danish and differently tailored experimental designs 
would be needed in order to fully explore this observation.

Finally, Shtyrov et al. (2011) have shown that high-frequency words elicit a larger MMN-like response than do comparable low-frequency words. Differences in frequencies between our stimuli are, however, unlikely to have driven the effects we see in the present study. at (i.e., [ad] and [at]) is the third most frequent word in the largest Danish written korpus, KorpusDK (www.ordnet.dk/korpusDK, including 56 million words), with $\sim 1,527,000$ occurrences. The most common written equivalents of [da] (da) and [ta] (tage, tag, and ta') have $\sim 134,000$ and $\sim 33,000$ occurrences, respectively. [ta] is thus the most infrequent word of the three words we used as stimuli (i.e., $a t, d a$, and $t a$ '), and we saw the strongest MMNm to the monomorphemic word forms with [t] (i.e., [ta] and [at]), and if anything, a stronger MMNm to $[\mathrm{da}]$ than $[\mathrm{ad}]$.

\section{Limitations}

Given the intended multipurpose design of the paradigm, the present study faces a couple of limitations. First, in order to unequivocally probe phonological representations with $\mathrm{MMN}$ paradigms, which is important for the claims we make with respect to e.g. FUL, one should optimally employ a relevant version of the many-to-one paradigm introduced by Phillips et al. (2000) and also used by Kazanina et al. (2006) and Hestvik \& Durvasula (2016). This entails using several allophones (differing systematically along a relevant dimension, e.g. VOT) within an individually-tested phonemic category as standards, as well as using a deviant that differs along the same dimension and with the same degree of acoustic difference from some of the standards as between some of the standards themselves. This paradigm has not been tested within a multifeature MMN paradigm where the use of 
each deviant depends on its particular feature being kept constant in the other deviants (Näätänen et al., 2004). Whether this would be feasible in combination with deviant features such as intensity, vowel quality and syllable structure as used in this study remains an empirical question. But since the multifeature MMN paradigm used in this study had not been attested before, we opted for a version of the paradigm that mirrored the original multifeature MMN paradigm as closely as possible. Eulitz \& Lahiri (2004) proposed using a multiple-token approach using e.g. three different tokens of the standard in order to "to simulate more natural speech perception conditions" (Eulitz \& Lahiri, 2004) which has been used by several studies investigating underspecification (Bonte et al., 2005 four tokens; Cornell et al., 2011 six tokens; 2013 three tokens; Eulitz \& Lahiri, 2004 three tokens; Scharinger et al., 2010 four tokens; 2011 ten tokens; Scharinger, Monahan, \& Idsardi, 2012b ten tokens; 2016 ten tokens [same as 2012b]; Schluter et al., 2016 five tokens; Tavabi et al., 2009 four tokens). While such an approach is certainly interesting in terms of increasing the ecological validity of linguistic MMN paradigms, it is not entirely clear that the approach would ensure probing phonological representations unless the relevant acoustic dimension is controlled and manipulated along the lines of the already mentioned many-to-one paradigm introduced by Phillips et al. (2000). Otherwise, the multiple-token approach may rather be tapping into e.g. online talkerspecific adaptations (Eisner \& Mcqueen, 2006; Norris, Mcqueen, \& Cutler, 2003). In broader terms, several previous MMN studies (e.g. Chládková et al., 2013; DehaeneLambertz, 1997; 2000; Näätänen et al., 1997; Winkler, Kujala, et al., 1999a; Ylinen et al., 2006) have been interpreted as probing phonological representations using singletoken paradigms.

Nonetheless, we cannot rule out that the observed asymmetry in this study pertains to 
an asymmetry of phonetic rather than phonological categories. In this light, it is relevant to consider recent extensions of the Natural Referent Vowel (NFR) framework (Polka \& Bohn, 2003; 2010) which have attempted to include consonants as well (Bundgaard-Nielsen, Baker, Kroos, Harvey, \& Best, 2015; Nam, 2014; Nam \& Polka, 2016), suggesting that one member of a contrast serves as a perceptual anchor (or referent) to the other during language acquisition by virtue of that member's psychoacoustic saliency. For vowels, these referents are at the extremes of the vowel inventory, and for consonants, stops have tentatively been suggested as referents for fricatives due to their steeper attack time (Nam, 2014; Nam \& Polka, 2016), and alveolar stops as referents for retroflex and dental stops (BundgaardNielsen et al., 2015). It may thus be that there is a psycholinguistic relevance to lowlevel feature detectors potentially sensitive to broad-spectrum noise in terms of increased psychoacoustic saliency for aspirated over non-aspirated sounds. The NFR framework posits that such perceptual asymmetries are strongest in infants, but still persist into adulthood. Hence, to assess its applicability for the observed asymmetry in this study, further studies assessing the degree of the potential asymmetry in infants would be needed.

Furthermore, Phillips et al.'s (2000) posited that most that behavioral data from twoalternative-forced-choice (2AFC) tasks, in fact, support the presence of phonetic rather than phonological categories. However, their point pertains only to the use of 2AFC tasks (also known as identification tasks) as behavioral evidence, not the use of oddball tasks as the one used in the present experiment. Interestingly, Scharinger et al. (2012a) used both an identification task and an oddball task (similar to the one used in the present study) and only found asymmetry effects in the oddball task. The authors explained this discrepancy by the nature of the oddball task which allowed the 
participants to build up a prediction of the forthcoming sounds, and this prediction was less precise for the standard carrying the underspecified feature, leading to an asymmetry in the ability to detect the oddballs, and thus tapping into phonological representations (Scharinger et al., 2012a).

Nonetheless, future research on underspecification in Danish would preferably employ the many-to-one paradigm in order to ensure probing phonological representations.

Finally, the support reported herein for underspecification of [spread] in Danish rests on our own preliminary hypothesis about this effect. There is no independent analysis available on [spread] as an underspecified feature more globally nor on Danish phonology within the FUL framework, which are thus advances that would be advantageous to pursue.

\section{Conclusion}

In the present study, we have shown a stronger $\mathrm{MMNm}$ to $[\mathrm{t}]$ when it was presented as an oddball among [d]s compared to when [d] was presented as an oddball among $[\mathrm{t}] \mathrm{s}$, a finding that was corroborated in a behavioral oddball task. At the same time, we did not find support for our hypothesis regarding effects of the phonetic context on the MMNm to language sounds.

We thus report on an asymmetry effect where the brain reacts differently to the same acoustic difference depending on the direction of presentation. Given the linguistic nature of the stimuli used in these experiments, we treat this asymmetry effect on the $\mathrm{MMNm}$ to $/ \mathrm{t} /$ and $/ \mathrm{d} /$ as tentative support for the notion of underspecification of the 
laryngeal feature [spread] (i.e., aspiration) in Danish. And given the potential role of under- and overspecification in phonological deficits, such as dyslexia, we speculate that there may be a role for paradigms similar to the current one in further exploring these aspects of phonological deficits.

Acknowledgments. This study was supported by the Aarhus University Faculty of Arts, The Danish National Research Foundation's grant to CFIN, the MINDLab grant from the Danish Ministry of Science, Technology and Innovation, as well as the Interacting Minds Centre's seed funding scheme. We thank Teija Kujala and Katrin Krumbholz for their insightful comments on an earlier version of this manuscript. 


\section{References}

Alho, K., Connolly, J. F., Cheour, M., Lehtokoski, A., Huotilainen, M., Virtanen, J., et al. (1998). Hemispheric lateralization in preattentive processing of speech sounds. Neuroscience Letters, 258(1), 9-12.

Alho, K., Tervaniemi, M., Huotilainen, M., Lavikainen, J., Tiitinen, H., Ilmoniemi, R. J., et al. (1996). Processing of complex sounds in the human auditory cortex as revealed by magnetic brain responses. Psychophysiology, 33(4), 369-375.

Basbøll, H. (2005). The Phonology of Danish. Oxford University Press.

Bishop, D. V. M., O’Reilly, J., \& McArthur, G. M. (2005). Electrophysiological evidence implicates automatic low-level feature detectors in perceptual asymmetry. Cognitive Brain Research, 24(1), 177-179. http://doi.org/10.1016/j.cogbrainres.2004.12.007

Boersma, P., \& Weenink, D. (2013, September 15). Praat: doing phonetics by computer. Retrieved from http://www.praat.org/

Bogliotti, C., Serniclaes, W., Messaoud-Galusi, S., \& Sprenger-Charolles, L. (2008). Discrimination of speech sounds by children with dyslexia: Comparisons with chronological age and reading level controls. Journal of Experimental Child Psychology, 101(2), 137-155. http://doi.org/10.1016/j.jecp.2008.03.006

Bonte, M. L., Mitterer, H., Zellagui, N., Poelmans, H., \& Blomert, L. (2005). Auditory cortical tuning to statistical regularities in phonology. Clinical Neurophysiology, 116(12), 2765-2774. http://doi.org/10.1016/j.clinph.2005.08.012

Bundgaard-Nielsen, R. L., Baker, B. J., Kroos, C. H., Harvey, M., \& Best, C. T. (2015). Discrimination of Multiple Coronal Stop Contrasts in Wubuy (Australia): A Natural Referent Consonant Account. PLoS ONE, 10(12), e0142054. http://doi.org/10.1371/journal.pone.0142054.t008

Catts, S. V., Shelley, A. M., Ward, P. B., Liebert, B., McConaghy, N., Andrews, S., \& Michie, P. T. (1995). Brain potential evidence for an auditory sensory memory deficit in schizophrenia. The American Journal of Psychiatry, 152(2), 213-219.

Chládková, K., Escudero, P., \& Lipski, S. C. (2013). Pre-attentive sensitivity to vowel duration reveals native phonology and predicts learning of second-language sounds. Brain and Langauge, 126(3), 243-252. http://doi.org/10.1016/j.bandl.2013.05.020

Cornell, S. A., Lahiri, A., \& Eulitz, C. (2011). "What you encode is not necessarily what you store": evidence for sparse feature representations from mismatch negativity. Brain Research, 1394, 79-89. http://doi.org/10.1016/j.brainres.2011.04.001

Cornell, S. A., Lahiri, A., \& Eulitz, C. (2013). Inequality across consonantal contrasts in speech perception: evidence from mismatch negativity. Journal of Experimental Psychology Human Perception and Performance, 39(3), 757-772. http://doi.org/10.1037/a0030862

Cousineau, D. (2005). Confidence intervals in within-subject designs: A simpler solution to Loftus and Masson's method. Tutorials in Quantitative Methods for Psychology, 1(1), 42-45.

Crowley, M. J., Wu, J., McCreary, S., Miller, K., \& Mayes, L. C. (2012). Implementation of false discovery rate for exploring novel paradigms and trait dimensions with ERPs. Developmental Neuropsychology, 37(6), 559-577. http://doi.org/10.1080/87565641.2012.694513 
Cummings, A., Madden, J., \& Hefta, K. (2017). Converging evidence for [coronal] underspecification in English-speaking adults. Journal of Neurolinguistics, 44, 147-162. http://doi.org/10.1016/j.jneuroling.2017.05.003

Cusack, R., \& Carlyon, R. P. (2003). Perceptual asymetries in audition. Journal of Experimental Psychology Human Perception and Performance, 29(3), 713. http://doi.org/10.1037/0096-1523.29.3.713

Dehaene-Lambertz, G. (1997). Electrophysiological correlates of categorical phoneme perception in adults. NeuroReport, 8(4), 919-924.

Dehaene-Lambertz, G. (2000). Cerebral specialization for speech and non-speech stimuli in infants. Journal of Cognitive Neuroscience, 12(3), 449-460.

Dehaene-Lambertz, G., Dupoux, E., \& Gout, A. (2000). Electrophysiological correlates of phonological processing: a cross-linguistic study. Journal of Cognitive Neuroscience, 12(4), 635-647.

Diesch, E., \& Luce, T. (1997). Magnetic mismatch fields elicited by vowels and consonants. Experimental Brain Research, 116(1), 139-152.

Eisner, F., \& Mcqueen, J. M. (2006). Perceptual learning in speech: Stability over time. The Journal of the Acoustical Society of America, 119(4), 1950. http://doi.org/10.1121/1.2178721

Elbro, C. (1996). Early linguistic abilities and reading development: A review and a hypothesis. Reading and Writing, 8(6), 453-485. http://doi.org/10.1007/BF00577023

Eulitz, C., \& Lahiri, A. (2004). Neurobiological evidence for abstract phonological representations in the mental lexicon during speech recognition. Journal of Cognitive Neuroscience, 16(4), 577-583.

Giegerich, H. J. (1992). English Phonology. Cambridge University Press.

Gramfort, A., Luessi, M., Larson, E., Engemann, D. A., Strohmeier, D., Brodbeck, C., et al. (2013). MEG and EEG data analysis with MNE-Python. Frontiers in Neuroscience, 7, 267. http://doi.org/10.3389/fnins.2013.00267

Gramfort, A., Luessi, M., Larson, E., Engemann, D. A., Strohmeier, D., Brodbeck, C., et al. (2014). MNE software for processing MEG and EEG data. NeuroImage, 86, 446-460. http://doi.org/10.1016/j.neuroimage.2013.10.027

Grønnum, N. (2005). Fonetik og fonologi - almen og dansk (3rd ed.). Copenhagen: Akademisk (Nørhaven, Viborg).

Hari, R., Hämäläinen, M., Ilmoniemi, R., Kaukoranta, E., Reinikainen, K., Salminen, J., et al. (1984). Responses of the primary auditory cortex to pitch changes in a sequence of tone pips: neuromagnetic recordings in man. Neuroscience Letters, 50(1-3), 127-132.

Hestvik, A., \& Durvasula, K. (2016). Neurobiological evidence for voicing underspecification in English. Brain and Langauge, 152, 28-43. http://doi.org/10.1016/j.bandl.2015.10.007

Hutters, B. (1985). Vocal fold adjustments in aspirated and unaspirated stops in Danish. Phonetica, 42(1), 1-24.

Iverson, G. K. (2008). Review of Brockhaus 1995 (Final devoicing in the phonology of German). Journal of Germanic Linguistics, 9(2), 255-264. http://doi.org/10.1017/S1040820700002900

Jaramillo, M., Alku, P., \& Paavilainen, P. (1999). An event-related potential (ERP) study of duration changes in speech and non-speech sounds. NeuroReport, 10(16), 3301. 
Jaramillo, M., Paavilainen, P., \& Näätänen, R. (2000). Mismatch negativity and behavioural discrimination in humans as a function of the magnitude of change in sound duration. Neuroscience Letters, 290(2), 101-104.

Kaukoranta, E., Sams, M., Hari, R., Hämäläinen, M., \& Näätänen, R. (1989). Reactions of human auditory cortex to a change in tone duration. Hearing Research, 41(1), 15-21.

Kazanina, N., Phillips, C., \& Idsardi, W. (2006). The influence of meaning on the perception of speech sounds. Proceedings of the National Academy of Sciences of the United States of America, 103(30), 11381-11386.

Kilner, J. M. (2013). Bias in a common EEG and MEG statistical analysis and how to avoid it. Clinical Neurophysiology, 124(10), 2062-2063. http://doi.org/10.1016/j.clinph.2013.03.024

Kilner, J. M., \& Friston, K. J. (2010). Topological inference for EEG and MEG. The Annals of Applied Statistics, 4(3), 1272-1290. http://doi.org/10.2307/29765554?ref=searchgateway:648e1d9a1f282f1e12df64627e4afe93

Kirmse, U., Ylinen, S., Tervaniemi, M., Vainio, M., Schroger, E., \& Jacobsen, T. (2007). Modulation of the mismatch negativity (MMN) to vowel duration changes in native speakers of Finnish and German as a result of language experience. International Journal of Psychophysiology, 67, 131-143. http://doi.org/10.1016/j.ijpsycho.2007.10.012

Koyama, S., Gunji, A., Yabe, H., Oiwa, S., Akahane-Yamada, R., Kakigi, R., \& Näätänen, R. (2000). Hemispheric lateralization in an analysis of speech sounds. Left hemisphere dominance replicated in Japanese subjects. Cognitive Brain Research, 10(1-2), 119-124.

Kriegeskorte, N., Simmons, W. K., Bellgowan, P. S. F., \& Baker, C. I. (2009). Circular analysis in systems neuroscience: the dangers of double dipping. Nature Neuroscience, 12(5), 535-540. http://doi.org/10.1038/nn.2303

Kuhl, P. K., Williams, K. A., Lacerda, F., Stevens, K. N., \& Lindblom, B. (1992). Linguistic experience alters phonetic perception in infants by 6 months of age. Science, 255(5044), 606-608.

Kujala, T., Tervaniemi, M., \& Schröger, E. (2007). The mismatch negativity in cognitive and clinical neuroscience: theoretical and methodological considerations. Biological Psychology, 74(1), 1-19. http://doi.org/10.1016/j.biopsycho.2006.06.001

Lage-Castellanos, A., Martínez-Montes, E., Hernández-Cabrera, J. A., \& Galán, L. (2010). False discovery rate and permutation test: an evaluation in ERP data analysis. Statistics in Medicine, 29(1), 63-74. http://doi.org/10.1002/sim.3784

Lahiri, A., \& Reetz, H. (2002). Underspecified recognition. Laboratory Phonology, 7, 637-676.

Lahiri, A., \& Reetz, H. (2010). Distinctive features: Phonological underspecification in representation and processing. Journal of Phonetics, 38(1), 44-59. http://doi.org/10.1016/j.wocn.2010.01.002

Lisker, L. (1977). Rapid versus rabid: A catalogue of acoustic features that may cue the distinction. Journal of the Acoustical Society of America, 62(S1), S77-S78. http://doi.org/doi:10.1121/1.2016377

Lisker, L. (1986). "Voicing" in English: a catalogue of acoustic features signaling/b/versus/p/in trochees. Language and Speech, 29(1), 3-11. http://doi.org/10.1177/002383098602900102 
Litvak, V., Mattout, J., Kiebel, S., Phillips, C., Henson, R., Kilner, J., et al. (2011). EEG and MEG data analysis in SPM8. Computational Intelligence and Neuroscience, 2011, 852961. http://doi.org/10.1155/2011/852961

Macmillan, N. A., \& Creelman, C. D. (2005). Detection Theory (2nd ed.). Routledge.

Miglietta, S., Grimaldi, M., \& Calabrese, A. (2013). Conditioned allophony in speech perception: An ERP study. Brain and Langauge, 126(3), 285-290. http://doi.org/10.1016/j.bandl.2013.06.001

Morey, R. D. (2008). Confidence intervals from normalized data: A correction to Cousineau (2005). Reason, 4(2), 61-64.

Nam, Y. (2014). The role of acoustic-phonetic bias in consonant manner perception. McGill University, Montreal.

Nam, Y., \& Polka, L. (2016). The phonetic landscape in infant consonant perception is an uneven terrain. Cognition, 155, 57-66. http://doi.org/10.1016/j.cognition.2016.06.005

Näätänen, R. (1992). Attention and Brain Function. Psychology Press.

Näätänen, R., Gaillard, A., \& Mäntysalo, S. (1978). Early selective-attention effect on evoked potential reinterpreted. Acta Psychologica, 42(4), 313-329.

Näätänen, R., Lehtokoski, A., Lennes, M., Cheour, M., Huotilainen, M., Iivonen, A., et al. (1997). Language-specific phoneme representations revealed by electric and magnetic brain responses. Nature, 385(6615), 432-434. http://doi.org/10.1038/385432a0

Näätänen, R., Paavilainen, P., \& Reinikainen, K. (1989). Do event-related potentials to infrequent decrements in duration of auditory stimuli demonstrate a memory trace in man? Neuroscience Letters, 107(1-3), 347-352.

Näätänen, R., Paavilainen, P., Rinne, T., \& Alho, K. (2007). The mismatch negativity $(\mathrm{MMN})$ in basic research of central auditory processing: a review. Clinical Neurophysiology, 118(12), 2544-2590. http://doi.org/10.1016/j.clinph.2007.04.026

Näätänen, R., Pakarinen, S., Rinne, T., \& Takegata, R. (2004). The mismatch negativity (MMN): towards the optimal paradigm. Clinical Neurophysiology, 115(1), 140-144. http://doi.org/10.1016/j.clinph.2003.04.001

Nielsen, A. H., Horn, N. T., Sørensen, S. D., McGregor, W. B., \& Wallentin, M. (2015). Intensive foreign language learning reveals effects on categorical perception of sibilant voicing after only 3 weeks. I-Perception, 6(6), 1-26. http://doi.org/10.1177/2041669515613674

Noordenbos, M. W. (2013). Phonological representations in dyslexia: Underspecified or overspecified? Radboud University, Nijmegen.

Noordenbos, M. W., \& Serniclaes, W. (2015). The Categorical Perception Deficit in Dyslexia: A Meta-Analysis. Scientific Studies of Reading, 19(5), 340-359. http://doi.org/10.1080/10888438.2015.1052455

Noordenbos, M. W., Segers, E., Serniclaes, W., \& Verhoeven, L. (2013). Neural evidence of the allophonic mode of speech perception in adults with dyslexia. Clinical Neurophysiology. http://doi.org/10.1016/j.clinph.2012.12.044

Noordenbos, M. W., Segers, E., Serniclaes, W., Mitterer, H., \& Verhoeven, L. (2012). Neural evidence of allophonic perception in children at risk for dyslexia. Neuropsychologia, 50(8), 1-8. http://doi.org/10.1016/j.neuropsychologia.2012.04.026

Norris, D., Mcqueen, J. M., \& Cutler, A. (2003). Perceptual learning in speech. Cognitive Psychology, 47(2), 204-238. 
Pakarinen, S., Lovio, R., Huotilainen, M., Alku, P., Näätänen, R., \& Kujala, T. (2009). Fast multi-feature paradigm for recording several mismatch negativities (MMNs) to phonetic and acoustic changes in speech sounds. Biological Psychology, 82(3), 219-226.

Pakarinen, S., Takegata, R., Rinne, T., Huotilainen, M., \& Näätänen, R. (2007). Measurement of extensive auditory discrimination profiles using the mismatch negativity (MMN) of the auditory event-related potential (ERP). Clinical Neurophysiology, 118(1), 177-185. http://doi.org/10.1016/j.clinph.2006.09.001

Phillips, C., Pellathy, T., Marantz, A., Yellin, E., Wexler, K., Poeppel, D., et al. (2000). Auditory cortex accesses phonological categories: an MEG mismatch study. Journal of Cognitive Neuroscience, 12(6), 1038-1055. http://doi.org/10.1037/0096-1523.3.4.686

Polka, L., \& Bohn, O.-S. (2003). Asymmetries in vowel perception. Speech Communication, 41(1), 221-231. http://doi.org/10.1016/S0167-6393(02)00105-X

Polka, L., \& Bohn, O.-S. (2010). Natural Referent Vowel (NRV) framework: An emerging view of early phonetic development. Journal of Phonetics. http://doi.org/10.1016/j.wocn.2010.08.007

Port, R. F., \& Dalby, J. (1982). Consonant/vowel ratio as a cue for voicing in English. Perception \& Psychophysics, 32(2), 141-152.

Rinne, T., Alho, K., Alku, P., Holi, M., Sinkkonen, J., Virtanen, J., et al. (1999). Analysis of speech sounds is left-hemisphere predominant at $100-150 \mathrm{~ms}$ after sound onset. NeuroReport, 10(5), 1113-1117.

Rinne, T., Särkkä, A., Degerman, A., Schröger, E., \& Alho, K. (2006). Two separate mechanisms underlie auditory change detection and involuntary control of attention. Brain Research, 1077(1), 135-143. http://doi.org/10.1016/j.brainres.2006.01.043

Ritter, W., Paavilainen, P., Lavikainen, J., Reinikainen, K., Alho, K., Sams, M., \& Näätänen, R. (1992). Event-related potentials to repetition and change of auditory stimuli. Electroencephalography and Clinical Neurophysiology, 83(5), 306-321.

Scharinger, M., Bendixen, A., Trujillo-Barreto, N. J., \& Obleser, J. (2012a). A sparse neural code for some speech sounds but not for others. PLoS ONE, 7(7), e40953. http://doi.org/10.1371/journal.pone.0040953

Scharinger, M., Lahiri, A., \& Eulitz, C. (2010). Mismatch negativity effects of alternating vowels in morphologically complex word forms. Journal of Neurolinguistics, 23(4), 383-399. http://doi.org/10.1016/j.jneuroling.2010.02.005

Scharinger, M., Merickel, J., Riley, J., \& Idsardi, W. J. (2011). Neuromagnetic evidence for a featural distinction of English consonants: sensor- and sourcespace data. Brain and Langauge, 116(2), 71-82. http://doi.org/10.1016/j.bandl.2010.11.002

Scharinger, M., Monahan, P. J., \& Idsardi, W. J. (2012b). Asymmetries in the processing of vowel height. Journal of Speech, Language, and Hearing Research : JSLHR, 55(3), 903-918. http://doi.org/10.1044/1092-4388(2011/110065)

Scharinger, M., Monahan, P. J., \& Idsardi, W. J. (2016). Linguistic category structure influences early auditory processing: Converging evidence from mismatch responses and cortical oscillations. NeuroImage, 128, 293-301. http://doi.org/10.1016/j.neuroimage.2016.01.003

Schluter, K., Politzer-Ahles, S., \& Almeida, D. (2016). No place for /h/: an ERP investigation of English fricative place features. Language, Cognition and Neuroscience, 31(6), 728-740. http://doi.org/10.1080/23273798.2016.1151058 
Serniclaes, W., Heghe, S. V., Mousty, P., Carré, R., \& Sprenger-Charolles, L. (2004). Allophonic mode of speech perception in dyslexia. Journal of Experimental Child Psychology, 87(4), 336-361. http://doi.org/10.1016/j.jecp.2004.02.001

Sharma, A., \& Dorman, M. (2000). Neurophysiologic correlates of cross-language phonetic perception. The Journal of the Acoustical Society of America, 107, 2697.

Shestakova, A., Brattico, E., Huotilainen, M., Galunov, V., Soloviev, A., Sams, M., et al. (2002). Abstract phoneme representations in the left temporal cortex: magnetic mismatch negativity study. NeuroReport, 13(14), 1813-1816.

Shtyrov, Y., \& Pulvermüller, F. (2002). Neurophysiological evidence of memory traces for words in the human brain. NeuroReport, 13(4), 521-525.

Shtyrov, Y., \& Pulvermüller, F. (2007). Language in the mismatch negativity design. Journal of Psychophysiology, 21(3), 176-187.

Shtyrov, Y., Kimppa, L., Pulvermüller, F., \& Kujala, T. (2011). Event-related potentials reflecting the frequency of unattended spoken words: A neuronal index of connection strength in lexical memory circuits? NeuroImage, 55(2), 658-668. http://doi.org/10.1016/j.neuroimage.2010.12.002

Shtyrov, Y., Kujala, T., Ahveninen, J., Tervaniemi, M., Alku, P., Ilmoniemi, R. J., \& Näätänen, R. (1998). Background acoustic noise and the hemispheric lateralization of speech processing in the human brain: magnetic mismatch negativity study. Neuroscience Letters, 251(2), 141-144.

Shtyrov, Y., Kujala, T., Lyytinen, H., Ilmoniemi, R. J., \& Näätänen, R. (2000). Auditory cortex evoked magnetic fields and lateralization of speech processing. NeuroReport, 11(13), 2893-2896.

Shtyrov, Y., Pihko, E., \& Pulvermüller, F. (2005). Determinants of dominance: Is language laterality explained by physical or linguistic features of speech? NeuroImage, 27(1), 37-47.

Shtyrov, Y., Smith, M. L., Horne, Henson, R., Nathan, P. J., Bullmore, E. T., \& Pulvermüller, F. (2012). Attention to language: novel MEG paradigm for registering involuntary language processing in the brain. Neuropsychologia, 50(11), 2605-2616. http://doi.org/10.1016/j.neuropsychologia.2012.07.012

Sussman, E. S. (2007). A new view on the MMN and attention debate. Journal of Psychophysiology, 21(3), 164-175.

Sussman, E. S. (2013). Attention Matters: Pitch vs. Pattern Processing in Adolescence. Frontiers in Psychology, 4, 333. http://doi.org/10.3389/fpsyg.2013.00333

Sussman, E. S., \& Gumenyuk, V. (2005). Organization of sequential sounds in auditory memory. NeuroReport, 16(13), 1519-1523.

Sussman, E. S., Ritter, W., \& Vaughan, H. G. (1998). Attention affects the organization of auditory input associated with the mismatch negativity system. Brain Research, 789(1), 130-138.

Sussman, E. S., Winkler, I., Huotilainen, M., Ritter, W., \& Näätänen, R. (2002). Topdown effects can modify the initially stimulus-driven auditory organization. Cognitive Brain Research, 13(3), 393-405.

Taulu, S., \& Simola, J. (2006). Spatiotemporal signal space separation method for rejecting nearby interference in MEG measurements. Physics in Medicine and Biology, 51(7), 1759-1768. http://doi.org/10.1088/0031-9155/51/7/008

Taulu, S., Kajola, M., \& Simola, J. (2004). Suppression of interference and artifacts by the Signal Space Separation Method. Brain Topography, 16(4), 269-275.

Tavabi, K., Elling, L., Dobel, C., Pantev, C., \& Zwitserlood, P. (2009). Effects of place of articulation changes on auditory neural activity: A 
magnetoencephalography study. PLoS ONE, 4(2), e4452.

http://doi.org/10.1371/journal.pone.0004452.t002

Tiitinen, H., May, P., Reinikainen, K., \& Näätänen, R. (1994). Attentive novelty detection in humans is governed by pre-attentive sensory memory. Nature, 372(6501), 90-92. http://doi.org/10.1038/372090a0

Timm, J., Weise, A., Grimm, S., \& Schröger, E. (2011). An asymmetry in the automatic detection of the presence or absence of a frequency modulation within a tone: a mismatch negativity study. Frontiers in Psychology, 2, 189. http://doi.org/10.3389/fpsyg.2011.00189/abstract

Vaux, B., \& Samuels, B. (2006). Laryngeal markedness and aspiration. Phonology, 22(03), 395-436. http://doi.org/10.1017/S0952675705000667

Wager, T. D., Keller, M. C., Lacey, S. C., \& Jonides, J. (2005). Increased sensitivity in neuroimaging analyses using robust regression. NeuroImage, 26(1), 99-113. http://doi.org/10.1016/j.neuroimage.2005.01.011

Wallentin, M. (2009). Putative sex differences in verbal abilities and language cortex: a critical review. Brain and Langauge, 108(3), 175-183. http://doi.org/10.1016/j.bandl.2008.07.001

Wallentin, M., Michaelsen, J. L. D., Rynne, I., \& Nielsen, R. H. (2014). Lateralized task shift effects in Broca"s and Wernicke"s regions and in visual word form area are selective for conceptual content and reflect trial history. NeuroImage, 101, 276-288. http://doi.org/10.1016/j.neuroimage.2014.07.012

Walter, M. A., \& Hacquard, V. (2004). MEG evidence for phonological underspecification (pp. 1-5). Presented at the BIOMAG 2004 the 14th International Conference on Biomagnetism, Boston, Massachusetts.

Winkler, I., Kujala, T., Tiitinen, H., Sivonen, P., Alku, P., Lehtokoski, A., et al. (1999a). Brain responses reveal the learning of foreign language phonemes. Psychophysiology, 36, 638-642.

Winkler, I., Lehtokoski, A., Alku, P., Vainio, M., Czigler, I., Csepe, V., et al. (1999b). Pre-attentive detection of vowel contrasts utilizes both phonetic and auditory memory representations. Cognitive Brain Research, 7(3), 357-369.

Worsley, K. J., \& Friston, K. J. (1995). Analysis of fMRI time-series revisited--again. NeuroImage, 2(3), 173-181. http://doi.org/10.1006/nimg.1995.1023

Ylinen, S., Shestakova, A., Huotilainen, M., Alku, P., \& Näätänen, R. (2006).

Mismatch negativity (MMN) elicited by changes in phoneme length: A crosslinguistic study. Brain Research, 1072(1), 175-185.

http://doi.org/10.1016/j.brainres.2005.12.004 


\section{Supplementary materials}

Sound 1: "da.wav" - standard and deviant sound [da], phonemic condition

Sound 2: "ta.wav" - standard and deviant sound [ta], phonemic condition

Sound 3: "ad.wav" - standard and deviant sound [ad], allophonic condition

Sound 4: "at.wav" - standard and deviant sound [at], allophonic condition

Sound 5: "mmn_dev_da.wav" - excerpt of multifeature MMN paradigm with [da] as the target deviant

Sound 6: "mmn_dev_ta.wav" - excerpt of multifeature MMN paradigm with [ta] as the target deviant

Sound 7: "mmn_dev_ad.wav" - excerpt of multifeature MMN paradigm with [ad] as the target deviant

Sound 8: "mmn_dev_at.wav" - excerpt of multifeature MMN paradigm with [at] as the target deviant

\section{Tab. S1}

\begin{tabular}{|c|c|c|c|c|c|c|c|c|}
\hline \multirow[t]{2}{*}{ Contrast } & \multicolumn{3}{|c|}{ Cluster-level } & \multicolumn{4}{|c|}{ Peak-level } & \multirow{2}{*}{$\begin{array}{c}\text { Coordinates } \\
\mathrm{x} \text { y } \mathrm{ms}\end{array}$} \\
\hline & $\boldsymbol{p}_{\mathrm{FWE}}$ & $\boldsymbol{p}_{\mathrm{UNC}}$ & $k$ & $\boldsymbol{p}_{\mathrm{FWE}}$ & $\boldsymbol{p}_{\mathrm{UNC}}$ & $F$ & $Z$ & \\
\hline $\begin{array}{l}\text { Phonemic } \\
\text { [dæ]-[dæ] }\end{array}$ & $\begin{array}{c}<0.001 \\
0.003 \\
0.057\end{array}$ & $\begin{array}{c}<0.001 \\
0.002\end{array}$ & $\begin{array}{l}34610 \\
15745\end{array}$ & $\begin{array}{l}0.012 \\
0.060 \\
0.349 \\
0.279 \\
0.385 \\
0.447\end{array}$ & $\begin{array}{l}<0.001 \\
<0.001 \\
<0.001 \\
<0.001 \\
<0.001 \\
<0.001\end{array}$ & $\begin{array}{l}56.410 \\
39.650 \\
24.500 \\
26.370 \\
23.660 \\
22.370\end{array}$ & $\begin{array}{l}4.710 \\
4.250 \\
3.620 \\
3.720 \\
3.580 \\
3.510\end{array}$ & $\begin{array}{rrr}-40 & -27 & 365 \\
49 & -30 & 323 \\
28 & -25 & 290 \\
-30 & -22 & 216 \\
-45 & -46 & 183 \\
-21 & -22 & 179\end{array}$ \\
\hline $\begin{array}{l}\text { Phonemic } \\
\text { [tæ]-[tæ] }\end{array}$ & $\begin{array}{c}<0.001 \\
0.041 \\
0.037\end{array}$ & $\begin{array}{c}<0.001 \\
0.028 \\
0.025\end{array}$ & $\begin{array}{r}26793 \\
7581 \\
7973\end{array}$ & $\begin{array}{l}0.108 \\
0.151 \\
0.239 \\
0.475 \\
0.502\end{array}$ & $\begin{array}{l}<0.001 \\
<0.001 \\
<0.001 \\
<0.001 \\
<0.001\end{array}$ & $\begin{array}{l}33.380 \\
30.540 \\
26.770 \\
21.060 \\
20.570\end{array}$ & $\begin{array}{l}4.030 \\
3.910 \\
3.740 \\
3.430 \\
3.400\end{array}$ & $\begin{array}{rrr}-15 & -52 & 122 \\
45 & -27 & 141 \\
-23 & 45 & 132 \\
-40 & 40 & 97 \\
-21 & 32 & 164\end{array}$ \\
\hline
\end{tabular}

Allophonic

[æd]-[æd]

n.s.

\begin{tabular}{lllllllll}
\hline & \multirow{2}{*}{0.001} & 0.001 & 19796 & $0.012<0.001$ & 56.330 & 4.710 & $23-22167$ \\
Allophonic & & & & $0.025<0.001$ & 47.970 & 4.500 & $34-22106$ \\
[æt]-[æt] & 0.002 & 0.001 & 18781 & $0.097<0.001$ & 35.030 & 4.090 & $-23-25106$ \\
& & & & $0.378<0.001$ & 23.630 & 3.580 & $-23-19147$
\end{tabular}


Table S1. Results of the SPMs of the individual conditions, i.e., testing the difference waves against 0 . The $\mathrm{x}, \mathrm{y}, \mathrm{z}$ coordinates refer to the $3 \mathrm{D}$ SPM volumes visualized in Fig. 3 (and S3) where $\mathrm{x}$ and y express the lateral plane (left-right) and the frontal plane (front-back) of the 64 x 64 pixel array of the sensors, respectively, and z express the temporal dimension $(0-400 \mathrm{~ms})$.

Tab. S2

\begin{tabular}{|c|c|c|c|c|c|c|c|c|}
\hline \multirow[t]{2}{*}{ Contrast } & \multicolumn{3}{|c|}{ Cluster-level } & \multicolumn{4}{|c|}{ Peak-level } & \multirow{2}{*}{$\frac{\text { Coordinates }}{x \text { y ms }}$} \\
\hline & $\boldsymbol{p}_{\mathrm{FWE}}$ & $\boldsymbol{p}_{\mathrm{UNC}}$ & $k$ & $\boldsymbol{p}_{\mathrm{FWE}}$ & $\boldsymbol{p}_{\mathrm{UNC}}$ & $F$ & $z$ & \\
\hline $\begin{array}{l}\text { Main effect of } \\
\text { Context }\end{array}$ & & & & & n.s. & & & \\
\hline \multirow{2}{*}{$\begin{array}{l}\text { Main effect of } \\
\text { Phoneme }\end{array}$} & 0.001 & 0.001 & 25918 & $\begin{array}{l}0.005 \\
0.044\end{array}$ & $\begin{array}{l}<0.001 \\
<0.001\end{array}$ & $\begin{array}{l}31.460 \\
23.250\end{array}$ & $\begin{array}{l}4.760 \\
4.180\end{array}$ & $\begin{array}{lll}-28 & -54 & 121 \\
-19 & -22 & 141\end{array}$ \\
\hline & 0.004 & 0.003 & 18410 & 0.014 & $<0.001$ & 27.420 & 4.490 & -3248133 \\
\hline $\begin{array}{l}\text { Interaction } \\
\text { effect of } \\
\text { Context }^{*} \\
\text { Phoneme }\end{array}$ & & & & & n.s. & & & \\
\hline
\end{tabular}

Table S2: Results of the SPMs of the flexible factorial design with Context and Phoneme as factors. The $\mathrm{x}, \mathrm{y}, \mathrm{z}$ coordinates refer to the 3D SPM volumes visualized in Fig. 3 (and S3), see the caption for Table S1 for more details. 

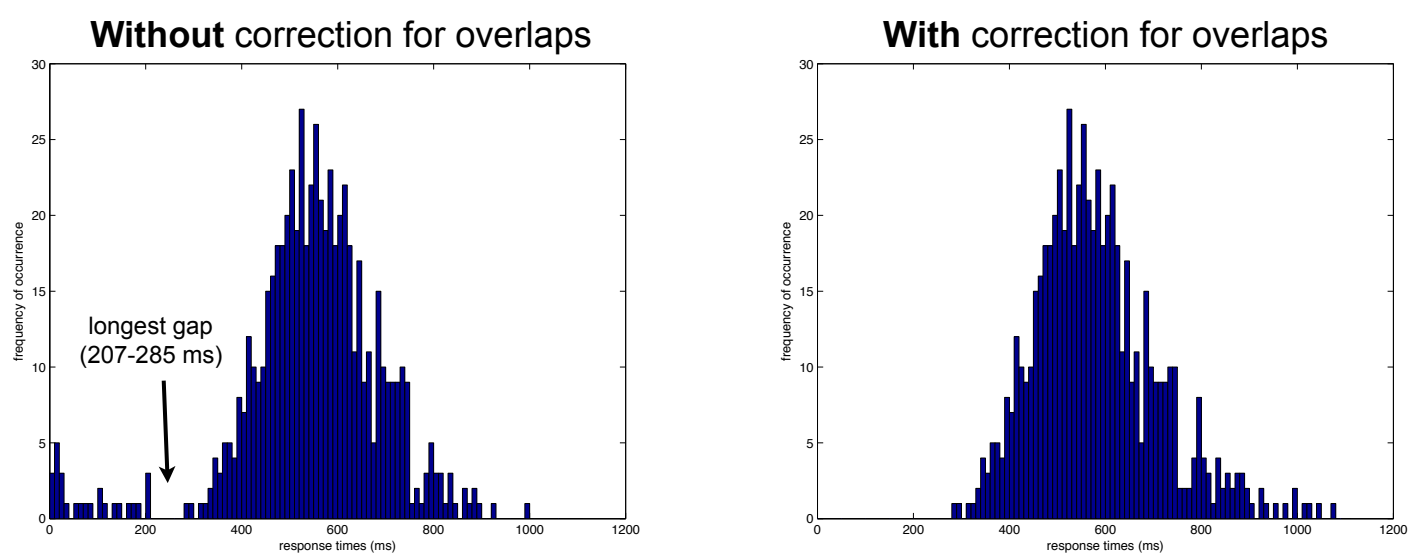

Figure S1. Histograms of the RTs from the behavioral paradigm.

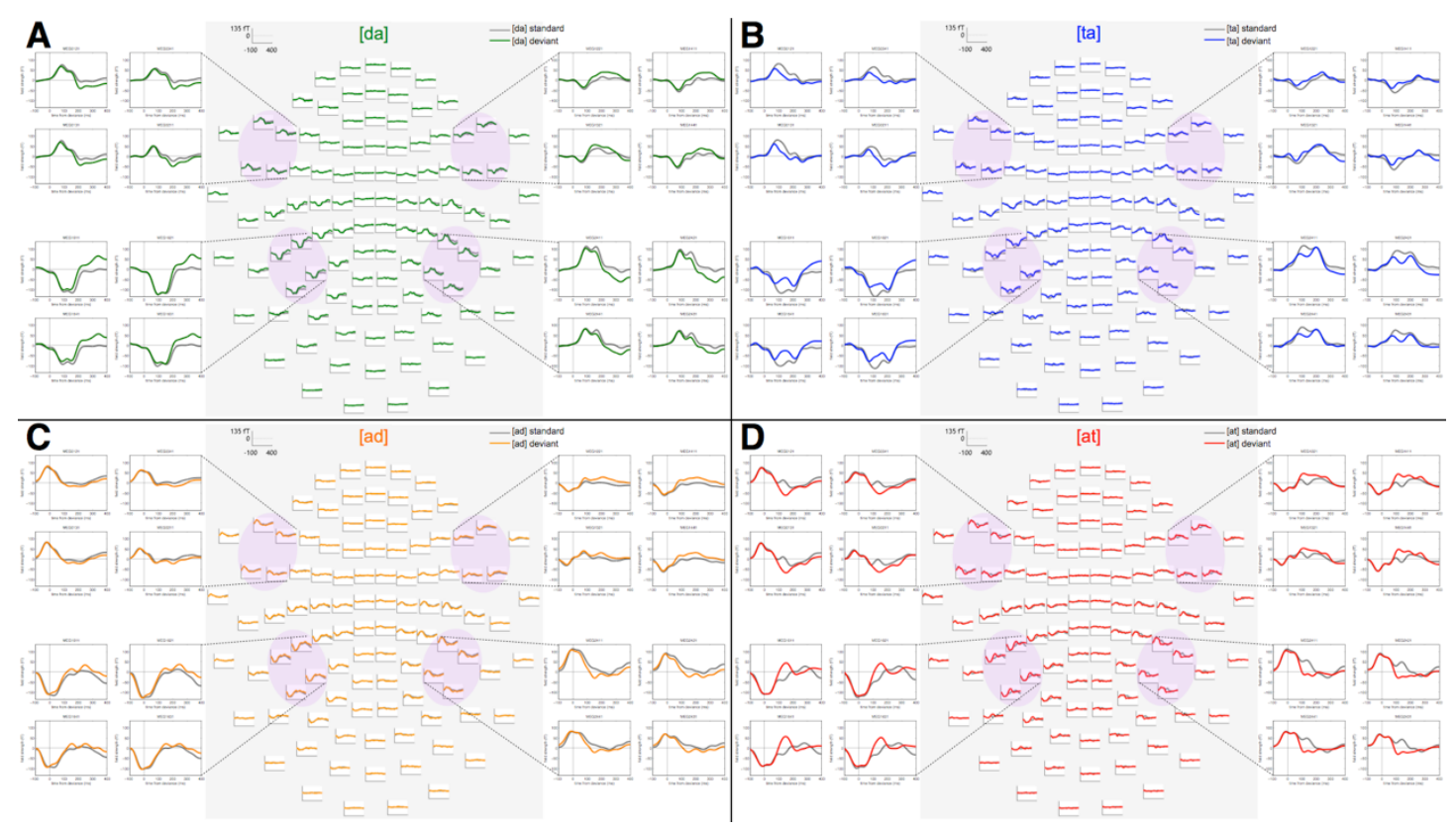

Figure S2: Full channel overview (of the magnetometers) for all four conditions (A: [da]; B: [ta]; C: [ad]; D: [at]). ERFs to the standard and the deviant. For each sensor site typically showing MMNm effects, four channels are highlighted: left anterior, left posterior, right anterior, and right posterior lateral sensor sites. Positive values reflect magnetic flux out of the scalp while negative values reflect magnetic flux into the scalp. Low-pass-filtered at $15 \mathrm{~Hz}$ for illustrative purposes. 
A $(\mathrm{MMR})$ to $[\mathrm{da}]$
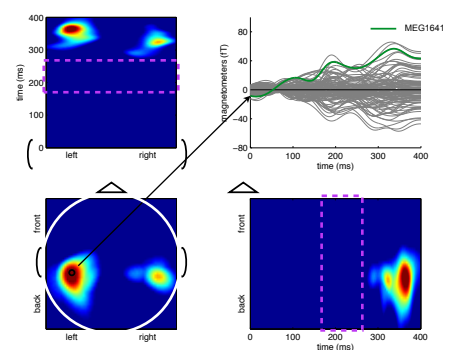

C no MMR to [ad]
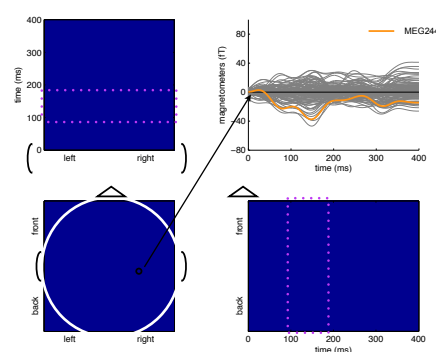

B $\quad$ MMR to [ta]

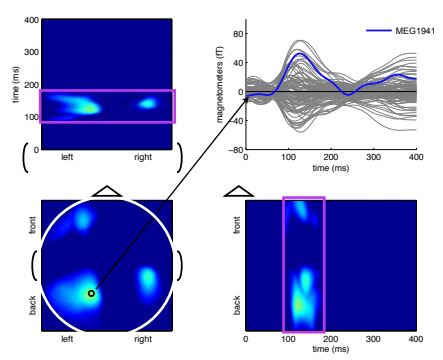

D $\quad$ MMR to [at]

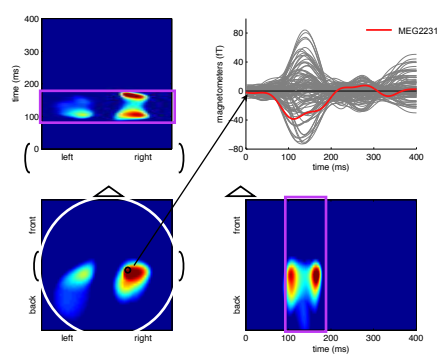

E Main effect of

Phoneme
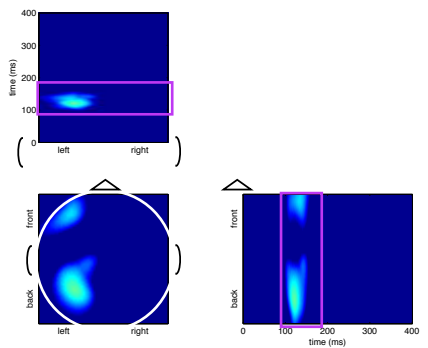

$$
\begin{aligned}
& \text { at } p_{F W E}<0.05 \text { : } \\
& \begin{array}{|c|c}
\hline \text { MMR } & \sim 100-180 \mathrm{~ms} \\
\hdashline \text { (MMR) } & \sim 180-260 \mathrm{~ms} \\
\cline { 1 - 2 } &
\end{array} \\
& \text { no MMR } \sim 100-180 \mathrm{~ms}
\end{aligned}
$$

Figure S3. The SPMs of the four individual conditions and the flexible factorial analysis, thresholded at $\mathrm{pFWE}<0.05$. See caption to figure 3 for more details. 